\title{
Title: Tbx1, a 22q11.2-encoded gene, is a link between alterations in fimbria myelination and cognitive speed in mice
}

Short title: Tbx1, fimbria myelination, and cognitive speed

\author{
Authors \\ Takeshi Hiramoto ${ }^{1 \dagger}$; Akira Sumiyoshi ${ }^{2,3 \dagger}$; Takahira Yamauchi ${ }^{1 \dagger}$; Kenji Tanigaki5; Qian \\ Shi $^{6}$, Gina Kang ${ }^{1}$; Rie Ryoke ${ }^{2}$; Hiroi Nonaka ${ }^{2}$; Shingo Enomoto ${ }^{7}$; Takeshi Izumi ${ }^{8}$; \\ Manzoor A. Bhat ${ }^{6}$; Ryuta Kawashima ${ }^{2}$; Noboru Hiroi ${ }^{1,6,10^{*}}$ \\ ${ }^{*}$ Corresponding author Noboru Hiroi, PhD \\ hiroi@uthscsa.edu \\ Department of Pharmacology; Department of Cellular and Integrative Physiology; \\ Department of Cell Systems and Anatomy \\ University of Texas Health Science Center, San Antonio \\ Room 211B \\ 7703 Floyd Curl Drive \\ San Antonio, TX 78229 \\ 12105674169 (tel) \\ $\dagger$ These authors contributed equally to the work.
}

\section{Affiliations}

${ }^{1}$ Department of Pharmacology, ${ }^{6}$ Department of Cellular and Integrative Physiology, ${ }^{10}$ Department of Cell Systems and Anatomy, University of Texas Health Science Center at San Antonio, Texas, 78229 USA.

2Institute of Development, Aging, and Cancer, Tohoku University, 4-1, Seiryo-cho, Aobaku, Sendai 980-8575, Japan.

${ }^{3}$ National Institutes for Quantum and Radiological Science and Technology, 4-9-1, Anagawa, Inage-ku, Chiba 263-8555, Japan.

${ }^{5}$ Research Institute, Shiga Medical Center, 5-4-30 Moriyama, Moriyama-shi, Shiga, Japan.

${ }^{7}$ Department of Psychiatry and Behavioral Sciences, Albert Einstein College of Medicine, 1300 Morris Park Avenue, Bronx, NY, 10461 USA. ${ }^{8}$ Department of Pharmacology and ${ }^{9}$ Advanced Research Promotion Center, Health Sciences University of Hokkaido, 1757 Kanazawa, Tobesu, Ishikari, Hokkaido 061-0293. 
45 Abstract

46 Copy number variants (CNVs) have provided a reliable entry point to identify structural

47 correlates of atypical cognitive development. Hemizygous deletion of human

48 chromosome $22 q 11.2$ is associated with impaired cognitive function; however, the

49 mechanisms by which numerous genes encoded in this CNV contribute to cognitive

50 deficits via diverse structural alterations in the brain remain unclear. This study aimed to

51 determine the cellular basis of the link between alterations in brain structure and

52 cognitive functions in a mouse model. The heterozygosity of $T b x 1, a 22 q 11.2$ gene,

53 altered the composition of myelinated axons in the fimbria, reduced oligodendrocyte

54 production capacity, and slowed the acquisition of spatial memory and cognitive

55 flexibility. Our findings provide a cellular basis for specific cognitive dysfunctions that

56 occur in patients with loss-of-function TBX1 variants and 22q11.2 hemizygous deletion. 
bioRxiv preprint doi: https://doi.org/10.1101/2021.03.29.437581; this version posted April 27, 2021. The copyright holder for this preprint (which was not certified by peer review) is the author/funder. All rights reserved. No reuse allowed without permission.

\section{Teaser}

60 A risk gene for autism alters myelin composition in the hippocampal connection and

61 slows cognitive speed. 


\section{INTRODUCTION}

Although copy number variants (CNVs) are rare and occur in $<1 \%$ of patients with any psychiatric disorder, they are robustly and consistently associated with developmental neuropsychiatric disorders $(1,2)$. Moreover, CNVs affect specific cognitive functions independent of clinically defined mental illness (3). Currently available pharmaceutical medications do not significantly improve cognitive deficits associated with many mental disorders due to a lack of understanding of their causative mechanistic targets.

Despite their robust association with cognitive impairments and psychiatric disorders, CNVs pose a challenge when attempting to understand the composition of contributory genes, as accurate identification of CNV-encoded genes contributing to human phenotypes remains difficult. A recent large-scale genome-wide exome screening study reported that protein-truncating variants of genes encoded in several large-sized CNVs are linked with autism spectrum disorder (ASD) (4). However, failure to detect similar variants of other CNV-encoded genes may be attributable to their rarity, as larger sample sizes enable the identification of more gene variants than smaller-scale analyses( 4 , 5). Moreover, variants in promoters and enhancers may contribute to phenotypes (6). Variants of CNV-encoded single genes may simply not exist, and single-gene hemizygosity or duplication, as part of a CNV, may play the role of a driver gene. Thus, there is a need to utilize complementary approaches to identify driver genes encoded by large CNVs.

There are more human and mouse studies of human chromosome $22 q 11.2$ deletion than other CNVs, given that it was found to be associated with mental illness much earlier than other CNVs (7). Hemizygous deletion of $22 q 11.2 \mathrm{CNVs}$ is robustly associated with 
87 diverse disorders, including ASD, attention-deficit/hyperactivity disorder, schizophrenia,

and intellectual disability (ID) (8). Moreover, individuals with 22q11.2 hemizygosity exhibit deterioration in specific cognitive functions, including the accuracy and speed of memory acquisition, executive functions, and social cognition (9-11). Further, cognitive impairment precedes and predicts the onset of schizophrenia among $22 q 11.2$

hemizygosity carriers $(12,13)$. In addition, recent large-scale imaging studies have demonstrated altered white matter integrity in the brains of $22 q 11.2$ hemizygous deletion carriers (14-16); no DTI-MRI analysis of mouse models of 22q11.2 hemizygosity have been reported. However, since many regions show altered white matter integrity and this CNV contains a minimum of 30 protein-coding genes, the exact causative associations among encoded genes, structural alterations, and atypical cognitive development remain unclear.

Rare loss-of-function variants (e.g., frameshift deletion) of $T B X 1$, a gene encoded by a 22q11.2 CNV, have been associated with ASD, ID, and seizures (17-20). However, these TBX1 variant carriers also exhibit single nucleotide variants (SNVs) in other genes (19), and only a few cases/families with those variants have been identified. The causative structural substrates in the brain mediating the impacts of $T b x 1$ deficiency on cognitive impairment remain unknown.

Mouse studies have provided a complementary means to address limitations of these human studies by systematically examining the roles of small chromosomal segments and individual genes in behaviors against a homogeneous genetic background (8, 2030). These studies have demonstrated that some, but not all, 22q11.2-encoded single genes contribute to select behavioral targets $(8,26,29)$. For example, our results have 
112 revealed that $T b x 1$ heterozygosity impairs social interaction and communication $(24,27$,

$11328,30)$. The present study aimed to determine the structural and cellular basis

114 underlying the effects of $T b x 1$ heterozygosity on specific cognitive functions in a 115 congenic mouse model. 


\section{RESULTS}

117 There are alterations in white matter microstructures in many brain regions of $22 q 11.2$

118 hemizygosity carriers (14-16). However, little is known regarding the exact nature of 119 altered white matter microstructures and driver genes that affect both the white matter 120 and cognitive functions.

\section{$122 \quad$ Analysis of white matter structures}

123 Tbx1 deficiency decreases fractional anisotropy (FA) signals in the fimbria

124 Tbx1 +/- mice and their +/+ littermates underwent ex vivo diffusion tensor imaging (DTI)125 magnetic resonance imaging (MRI). We analyzed 19 brain regions (Fig. S1), as defined 126 by the standard regional classification of the mouse brain (31). The FA value is the most 127 histologically validated DTI-MRI metric (32). However, since FA signals of $<0.3$ are not 128 reliably correlated with the degree of myelination (33) and cannot be accurately aligned

129 across individual animals (34), we selected regions with FA values $\geq 0.3$. The corpus 130 callosum, anterior commissure, internal capsule, and fimbria met this criterion (Fig.

131 S2A). The fimbria was the only region exhibiting a significant change: FA values were

132 lower in $+/-$ mice than in $+/+$ mice (Fig. 1). Consistently, the fimbria exhibited the largest

133 effect size for genotype-dependent differences in FA values (Fig. S2B). There were no 134 significant differences in axial diffusivity (AD), radial diffusivity (RD), or mean diffusivity 135 (MD) values between +/+ and +/- mice (Fig. S3-5).

139 Tbx1 deficiency reduces myelination in the fimbria 
140 DTI-MRI analysis of the mouse brain has limited spatial resolution, as well as technical

141 and interpretative limitations $(32,35)$. The structural classifications of Ma et al. (31)

142 include the fimbria, fornix, stria terminalis, and hippocampal commissure in the "fimbria".

143 To circumvent these limitations and histologically validate the DTI-MRI findings, we used

144 the non-hydroscopic gold-phosphate complex Black-Gold II (36). This method provides

more consistent staining than hydroscopic gold chloride staining and higher contrast and resolution than lipid soluble dyes (e.g., Luxol Fast Blue). Black-Gold II also directly stains myelin, unlike markers of myelin components (e.g., myelin basic protein [MBP]), which may not perfectly correlate with the degree of myelination. We examined regions with the largest and second largest effect sizes among FA values $\geq 0.3$ : the fimbria and corpus callosum (Fig. S2B; S6). The intensity of gold staining was lower in the anterior fimbria of $+/-$ mice than in that of $+/+$ mice (Fig. 2A). There was no statistically detectable between-genotype difference in the posterior fimbria or anterior/posterior corpus callosum (Fig. 2B-D).

\section{$\underline{T b x 1 \text { deficiency reduces large myelinated axons in the fimbria }}$}

We used electron microscopy (EM) to characterize the myelination of axons in the fimbria and corpus callosum at the ultrastructural level. Myelination appeared thicker and thinner in the fimbria and corpus callosum, respectively, of $+/-$ mice than in that of $+/+$ mice (Fig. 3AB). We compared g-ratios (i.e., the ratio of axon diameter to the axon + myelin diameter) to quantitatively evaluate relative myelin thickness (Fig. 3C, D). The gratios of $+/+$ mice plateaued slightly above 0.8 , which is an expected value for the optimal efficiency of axon myelination in the central nervous system (CNS) (37). The gratios of +/- mice were smaller (i.e., relatively thicker myelin sheath) in the fimbria (Fig. 3C), but not in the corpus callosum (Fig. 3D). Volume is a limiting factor in the CNS: The 
myelination efficiency steeply decreases when myelin thickness deviates from the

optimal g-ratio ( 0.8) (37) regardless of whether it is hyper- or hypo-myelination.

167 Therefore, this gene deficiency results in a functionally sub-optimal population of axons

168 in the fimbria.

A further in-depth analysis revealed that 1) myelin was thicker in axons with diameters

$171 \geq 700 \mathrm{~nm}$ to $<1,700 \mathrm{~nm}$ in the fimbria of $+/-$ mice than of $+/+$ mice (Fig. 3E; Fig. S7A); 2)

172 there were proportionally fewer myelinated axons $\geq 1,200 \mathrm{~nm}$ in diameter in the fimbria of

$173+$ +- mice than of +/+ mice (Fig. S8A; S-Table 1); and 3) there were no myelinated axons

$174 \geq 1,700 \mathrm{~nm}$ in diameter in the fimbria of +/- mice (Fig. 3E; S8A). In the corpus callosum,

myelin was thinner in axons with diameters between 1,000 nm and 1,400 nm in +/- mice

176 than in $+/+$ mice (Fig. 3F). The relative proportion of axons in the corpus callosum was

increased in axons between $\geq 400 \mathrm{~nm}$ and $<800 \mathrm{~nm}$ in diameter and was decreased in

axons $\geq 800 \mathrm{~nm}$ in diameter in +/- mice (Fig. S8B; S-Table 1). There were no myelinated

corpus callosum axons with diameters $\geq 2,000 \mathrm{~nm}$ in +/- mice (Fig. 3F; Fig. S8B).

In sum, Tbx1 heterozygous mice lacked large $(\geq 1,700 \mathrm{~nm})$ myelinated axons and corpus callosum of +/- mice, axons with diameters ranging from 1,000 to 1,400 nm were hypomyelinated. In addition, +/- mice exhibited proportionally more myelinated axons with diameters between $400 \mathrm{~nm}$ and $800 \mathrm{~nm}$ but less myelinated axons with diameters $186 \geq 800 \mathrm{~nm}$ in the corpus callosum.

$\underline{T b x 1 \text { heterozygosity impacts a molecule critical for early oligodendrogenesis }}$ 
190 Oligodendrocytes and their precursor cells are present locally in the fimbria and, to a 191 lesser extent, in the corpus callosum. The molecular steps through which Tbx1 impacts 192 oligodendrogenesis and myelination remains unknown. Given that Tbx1 mRNA is 193 reduced in the fimbria and corpus callosum of Tbx1 +/- mice compared to +/+ mice (Fig. 194 4), we examined the impact of a dose reduction of $T b x 1$ mRNA on molecules functionally 195 critical for each step of oligodendrogenesis and myelination in 2- to 3-month-old Tbx1 +/196 and +/+ littermates, using qRT-PCR. The myelinating process of the fimbria starts in the 197 second neonatal week and reaches its peak around postnatal day 24-37 in rodents (38).

Ng2 (Cspg4) and Pdfgr2, markers of oligodendrocyte precursor cells, are functionally required for the production of oligodendrocyte precursor cells $(39,40)$. We found that 201 mRNA levels of $\mathrm{Ng} 2$ and, but not of Pdgrf2, were selectively lower in the fimbria of +/202 mice than in that of $+/+$ mice (Fig. 4A). There was no detectable difference in $\mathrm{Ng} 2$ or

Pdgfr2 mRNA levels in the corpus callosum between $+/+$ and $+/-$ mice (Fig. $4 \mathbf{B}$ ). MBP is essential for the maintenance of myelin and is involved in the adhesion and compaction of the cytosolic membrane leaflets that form the structural basis of multilayered myelin $(41,42)$. Myelin oligodendrocyte glycoprotein (MOG) is a marker of mature oligodendrocytes and myelin, although it is not functionally critical for myelin formation or maintenance (43). No differences in MBP or MOG levels were observed in the fimbria or corpus callosum between $+/+$ and +/- mice (Fig. 4AB). This in vivo analysis indicated that $T b x 1$ heterozygosity selectively impacts the very early molecular step of oligodendrogenesis locally in the fimbria but has no effect on molecules required for myelin formation and maintenance in this location. 
215 Another source of oligodendrocytes in the fimbria is the population of adult neural

216 progenitor cells in the subventricular zone (44-47), which is distinct from those

217 generating neurons (48). Given the enrichment of Tbx1 protein in the adult subventricular

218 zone (SVZ) (24), we aimed to determine whether Tbx1 heterozygosity affects the cell-

219 autonomous capacity of this oligodendrocyte population. Progenitor cells were taken

220 from the lateral ventricular wall, including the subventricular zone, of 3-week-old Tbx1+/-

221 and +/+ littermates and cultured and differentiated into oligodendrocytes in vitro.

222 Progenitor cells derived from the subventricular zone of $T b x 1+/$ - mice produced fewer

223 O4-positive immature and mature oligodendrocytes than those derived from $+/+$ mice

224 (Fig. 5AB). This in vitro assay demonstrated that Tbx1 heterozygosity reduced

oligodendrocyte production from progenitor cells of the SVZ in a cell-autonomous manner.

DTI-MRI analysis detected the region exhibiting the most robust alteration in white matter integrity. This observation was validated using Black-Gold II staining, which provided a higher anatomical resolution of the net myelination levels. Although decreased FA values and reduced net myelin signals are suggestive of less myelin, axonal degeneration, reduced axonal density, or changes in axonal organization (49), our EM analyses complemented these assessments of the net signal intensities by demonstrating a loss of large myelinated axons in the fimbria and reduced myelination in axons with specific diameters in the corpus callosum. Our qRT-PCR and in vitro analyses further indicated that Tbx1 heterozygosity reduced levels of the molecule needed for the generation of local oligodendrocyte precursor cells and the production capacity of oligodendrocytes in 238 the lateral ventricular wall. 
240 Individuals with 22q11.2 hemizygous deletions exhibit lower scores on measures of attention, 241 executive function, processing speed, visual memory, visuospatial skills, and social cognition

$242(9,11)$. However, the link between structural alterations caused by single $22 q 11.2$ genes and 243 changes in cognitive function remains unknown. In addition, although human studies have 244 reported an association between loss-of-function $T B X 1$ variants and developmental

Tbx1 heterozygosity slows the acquisition of spatial reference memory

The spatial reference memory version of the Morris water maze requires an intact fimbria, whereas the visual cued version depends on the dorsal striatum in rodents $(50,51)$. Humans with 22q11.2 hemizygosity exhibit impaired spatial processing and memory $(9,52-54)$.

Although a previous study reported that spatial reference memory retention and recall in the Morris water maze were normal in a mouse model of $22 q 11.2$ hemizygosity (55), no studies have investigated these capacities in the acquisition phase.

Tbx1 +/- mice exhibited delayed spatial memory acquisition in the Morris water maze (Fig. 6A-C). In contrast, there was no between-genotype difference in the re-probe test (Fig. 6D) or during visual cue memory acquisition (Fig. 6E). These data indicate that Tbx1 heterozygosity impairs the acquisition speed of fimbria-dependent spatial reference memory, but not its retention or recall, or fimbria-independent visual cued memory.

$\underline{T b x 1 \text { heterozygosity slows the acquisition of discrimination and cognitive flexibility }}$ 
265 Individuals with 22q11.2 hemizygous deletion also exhibit impairments in executive functions

266 (9). Congenic mouse models of $22 q 11.2$ hemizygosity require an increased number of trials

267 to reach the criteria for simple discrimination and reversal learning (56) or extradimensional

268 shifting (EDS) (57). However, the individual 22q11.2 genes contributing to impairments in

269 executive functions remain unclear. In humans, prefrontal cortical lesions increase the

270 number of trials required to reach the criterion of attentional set shifting; on the other hand,

271 hippocampal lesions affect the latency for completing each trial (58). In rodents, orbitofrontal

272 cortical lesions increase the number of trials required to achieve reversal of the intra-

273 dimensional set (IDS-IV rev) $(59,60)$, although there have been no mouse studies regarding

274 the latency for achieving attentional set shifting. Tbx1+/- mice lacked detectable white matter

275 alterations in the basal forebrain or cortex (see Fig. S2-5) but exhibited altered myelination in

276 the fimbria. Thus, we reasoned that $T b x 1+/-$ mice may exhibit altered latency in completing

277 attentional set shifting but may be unaffected in terms of the attentional set-shifting task

278 requiring the prefrontal cortex (number of trials needed to reach a criterion).

There was no between-genotype difference in the number of trials required to complete each phase of attentional set shifting (Fig. 7A). In contrast, +/- mice were slower in completing each trial of attentional set shifting, most significantly in simple discrimination (SD) and IDS-IV rev (Fig. 7B).

$\underline{T b x 1}$ heterozygosity has no detectable effects on olfactory responses

286 Consistent with the lack of detectable alterations in the white matter integrity of the neocortex, amygdala, and olfactory bulb (Fig. S2-S5), there was no between-genotype 288 difference in responses or habituation to non-social and social olfactory cues (Fig. S9). 289 This observation suggests that Tbx1 heterozygosity does not exert non-specific effects 
290 on visual, olfactory, or tactile perception or on the general motivation to approach an

291 object or odorants.

292

293 In sum, our behavioral analysis identified a highly demarcated deficit in the acquisition of

294 fimbria-dependent cognitive tasks in Tbx1 +/- mice. 


\section{DISCUSSION}

The cellular, structural, or cognitive consequences of loss-of-function TBX1 variants in humans remain unclear. A parallel analysis of structural and behavioral measures in a congenic mouse model of $T b x 1$ heterozygosity indicated that $T b x 1$ deficiency caused highly demarcated changes in the structural features of the brain, including reduced production of oligodendrocytes, suboptimal composition of myelination in the fimbria and corpus callosum, and loss of large myelinated axons in the fimbria and corpus callosum. These structural alterations impacted fimbria-dependent cognitive functions: Tbx1 heterozygous mice exhibited increased latency to acquire spatial memory, simple discrimination, and reversal of intra-dimensional shift. Our findings are predictive of behavioral and structural alterations in carriers of loss-of-function TBX1 variants in humans. Moreover, as individuals with 22q11.2 hemizygosity exhibit impairments in cognitive speed $(9,11,61)$ as well as altered white matter integrity in the hippocampal projection fibers $(14-16,62)$, our data offer insight into the genetic and cellular substrates of these structural and behavioral alterations in carriers of 22q11.2 hemizygosity.

From a technical perspective, our combined analytical approach overcame the weaknesses associated with each technique. DTI-MRI can simultaneously screen many regions and determine the brain regions with the largest effect sizes. However, it does not identify the exact nature of altered white matter signals. Black-Gold II staining allows better resolution and detection of the reduction in net myelin density. However, gold staining was not effective in detecting the subtle effect of $T b x 1$ heterozygosity on the myelination of medium axons in the corpus callosum. Although EM is labor-intensive and is not suitable for screening to identify relevant regions in the entire brain, this ultrastructural analysis revealed subtle and selective myelin alterations in large and 
320 medium axons. Therefore, a lack of detectable signal alterations in DTI-MRI or gold

321 staining should not be considered as definitive. Moreover, an in vitro culture assay of

322 oligodendrocyte precursor cells provides not only a means for evaluating gene effects on

oligodendrogenesis but also a screening method for evaluating the effect of manipulating other genes and therapeutic ligands.

The observations that $\mathrm{Ng} 2 \mathrm{mRNA}$ was reduced in the fimbria (see Fig. 4A) while markers of mature oligodendrocytes were not (see Fig. 4A) are seemingly difficult to reconcile. Given that the fimbria of +/- mice contained hyper-myelinated medium axons but was devoid of large myelinated axons, it is possible that the effects of these positive and negative alterations on the net amount of MBP and MOG mRNA cancel out in in the fimbria. Moreover, as myelin was selectively reduced in the anterior fimbria only (see Fig. 2AB), such a regionally limited effect may be difficult to detect in the whole fimbria tissue used for qRT-PCR.

The absence of large myelinated axons in the fimbria of $+/$ - mice may be attributable to a reduced number of oligodendrocytes. Our in vivo data indicated that Tbx1 heterozygosity impacts $\mathrm{Ng2}$, a molecule required for the production of oligodendrocyte precursor cells, in the fimbria. Our in vitro analysis further revealed that fewer oligodendrocytes are produced from postnatal progenitor cells in +/- mice. Given their higher need for metabolic support from myelin and oligodendrocytes (63-65), a reduced number of oligodendrocytes may lead to degeneration of large axons. Alternatively, but not mutually exclusive, $T b x 1$ heterozygosity may lead to selective inactivation of largediameter axons and consequently reduced myelination of those axons, as oligodendrocytes tend to myelinate electrically active axons (66). In either case, the 
345 remaining oligodendrocytes may have instead myelinated medium axons in the fimbria,

346 which would explain the hyper-myelination of medium axons observed in the present

347 study.

349 Oligodendrocytes in the subventricular zone postnatally migrate to the fimbria and

350 corpus callosum (47). In mice, Tbx1 protein is postnatally enriched in the subventricular

351 zone (24). Reduced myelination of medium-diameter axons in the corpus callosum-as

352 well as a lack of large myelinated axons in the fimbria-may have also occurred due to

353 reduced postnatal migration of oligodendrocytes from the subventricular zone of $T b x 1+/-$

354 mice (see Fig. 3EF). It remains unclear how local oligodendrocyte precursor cells in the

355 fimbria and oligodendrocytes postnatally provided from the subventricular zone

356 contribute to the myelination of axons of different sizes. There is a need for further

357 studies to explore the molecular mechanisms underlying the role of Tbx1 in myelin

358 composition within the fimbria and corpus callosum.

Robust structural alterations in the fimbria exerted effects on the acquisition speed of spatial memory in the Morris water maze and cognitive flexibility in the attentional set shifting task. The first day of the Morris water maze reflects chance-level performance since the mice have not acquired a spatial map for the location of the platform. From day 2 onward, the speed of mastering the spatial map is reflected by the latency to reach the platform, with $+/$ - mice exhibiting a significant delay. When mice encounter the first discrimination task or reversal of intra-dimensional shift task, they are likely to face difficulty. In the present study, +/+ mice exhibited longer latencies to complete those 
exhibited the most significant delays in completing those phases, suggesting that Tbx1 deficiency impairs the ability to quickly master cognitively difficult tasks.

Our single-gene analysis provides a valid first step for deconstruction and reconstruction of the mechanistic composition of CNV-encoded genes in terms of their association with specific behavioral and structural dimensions. We previously reported that gene-dose

$(27,30)$, and working memory $(24,28)$. The present findings further demonstrate the effects of $T b \times 1$ heterozygosity on the myelin composition of the fimbria and its cognitive functions. However, we cannot exclude the possibility that deficiency of other $22 \mathrm{q} 11.2$ driver genes also contributes to similar and other cognitive deficits (29). Moreover, it is possible that other cellular mechanisms exist for social interaction and communication deficits of $T b x 1$ heterozygosity. Since 22q11.2 CNVs also include genes without an apparent role in any dimension (i.e., non-contributory genes) $(20,22,29,67,68)$, there is a need to comprehensively investigate each encoded single gene to elucidate the mechanisms underlying the effects of this CNV on behavioral dimensions. It should be cautioned, however, that a genotype may not impact a dimension as a unit and instead impact variables within a dimension (69)

The structural alterations and cognitive deficits observed in the present study are not unique to $T b x 1$ heterozygosity or $22 q 11.2 \mathrm{CNVs}$. Lower FA values have been reported in the fimbria/fornix of individuals with idiopathic ASD (70) and schizophrenia (71). Slow processing speed in individuals with idiopathic ASD is correlated with low FA values, but not with $M D, R D$, or $A D$ values, in the whole brain (72). Individuals with idiopathic ASD also exhibit impairments in difficult cognitive tasks (73). A selective loss of extra-large 
394 myelinated axons has been observed in the brains of humans with ASD (74). Moreover, 395 patients with idiopathic schizophrenia exhibit impaired processing speed across

396 numerous cognitive dimensions, including attention, memory, spatial processing, 397 emotional identification, and sensorimotor capacity $(75,76)$. Previous studies have also 398 reported that other oligodendrocyte-related genes are dysregulated in brain samples 399 from individuals with ASD and genetic mouse models for ASD (77-81). Taken together, 400 our findings open a new window for investigating the potential substrates of altered 401 cognitive speed in carriers of TBX1 SNVs, 22q11.2 and other CNVs, and in idiopathic cases of ASD and schizophrenia.

We screened for specific brain regions using DTI-MRI imaging. However, our resolution (150 $\mu \mathrm{m}$ isotropic voxel) may not have been sufficient for detecting subtle alterations.

Although DTI-MRI analysis revealed significant differences in the FA values for the fimbria only, EM analysis revealed less myelination exclusively in medium-sized axons in the corpus callosum of $+/$ - mice as well. If the gene deficiency affects a specific structural set or axons with a certain diameter, it would be difficult to detect such subtle effects using DTI-MRI. Therefore, the finding regarding the absence of detectable alterations based on the DTI-MRI analysis of other regions should be interpreted cautiously.

We interchangeably used male and female mice for various analyses, as individuals with 22q11.2 hemizygosity do not exhibit a sex bias for schizophrenia or ASD diagnosis (82) or for various cognitive capacities, including set-shifting, memory, and processing speed $(9,11)$. The number of currently identified TBX1 loss-of-function mutations is too small to 
418 determine a sex bias, however. Thus, there is a need for further research to determine 419 the precise impact of sex on various phenotypes.

\section{MATERIALS AND METHODS}

425 Experimental Design

426 This study was designed to determine the structural and cellular bases underlying 427 specific cognitive functions affected by $T b x 1$ heterozygosity in a congenic mouse model.

428 Specifically, we screened the most robust microstructural alterations using DTI-MRI, 429 histologically validated the findings through gold staining, identified ultra-structural bases 430 using EM, and determined the in vitro oligodendrocyte production capacity. After 431 demonstrating that $T b x 1$ heterozygosity alters myelin composition in the fimbria, we 432 evaluated fimbria-dependent and fimbria-independent cognitive functions using the 433 Morris water maze, attentional set shifting, and olfactory responses and habituation.

\section{Mice}

436 The protocols for animal handling and use were approved by the Animal Care and Use

437 Committee of the Albert Einstein College of Medicine, University of Texas Health

Science Center at San Antonio and Tohoku University in accordance with National

439 Institutes of Health $(\mathrm{NIH})$ guidelines.

$441 \underline{T b \times 1^{+/-} \text {mice }}$ This mouse model was a congenic strain with a C57BL/6J background. The 
$443>10$ generations to control for biased genetic backgrounds (83). Given that there are no

sex biases in the prevalence of schizophrenia or ASD (82), set-shifting, spatial working memory, spatial planning, processing speed, or other cognitive domains $(9,11)$ among carriers of 22q11.2 hemizygosity, we used either male or female mice for the various analyses.

We determined genotypes of mice using three primers: forward

TTGGTGACGATCATCTCGGT and reverse ATGATCTCCGCCGTGTCTAG to detect the +/+ genotype, as well as an additional reverse AGGTCCCTCGAAGAGGTTCA to detect the + - genotype.

Sample preparation: We performed ex vivo MR scanning to achieve a high resolution and high signal-to-noise ratio since it allows a long scan time and involves the use of a contrast agent. In accordance with standard procedures (84), 4-month old female mice were anesthetized using pentobarbital (60 mg/kg, i.p.) and transcardially perfused using $30 \mathrm{~mL}$ of $0.01 \mathrm{M}$ phosphate-buffered saline (PBS) that contained $2 \mathrm{mM}$ of ProHance (Bracco-Eisai Co., Ltd, Tokyo, Japan) and $1 \mu \mathrm{L} / \mathrm{mL}$ heparin (1,000 USP units $/ \mathrm{mL}$ ), followed by $30 \mathrm{~mL}$ of $4 \%$ paraformaldehyde (PFA; Wako, Tokyo, Japan) containing 2 $\mathrm{mM}$ ProHance. The head was decapitated, following which the skin, lower jaw, ears, and cartilaginous nose tip were removed. The skull structure containing the brain tissue was post-fixed in fixative (4\% PFA and $2 \mathrm{mM}$ ProHance) overnight at $4^{\circ} \mathrm{C}$. Subsequently, it was transferred to buffer (0.01 M PBS, $0.02 \%$ sodium azide, and $2 \mathrm{mM}$ ProHance) at $4^{\circ} \mathrm{C}$ overnight. Next, the brain tissues were placed in fresh buffer $(0.01 \mathrm{M} \mathrm{PBS}, 0.02 \%$ sodium azide + $2 \mathrm{mM}$ ProHance). Immediately before scanning, we immersed ex vivo mouse brains in Fomblin (Sigma-Aldrich, St Louis, MO), which is a perfluorocarbon 
that reduces susceptibility artifacts at the interface and limits intra-scanning sample dehydration.

MRI acquisition: MRI data were acquired using a 7.0-T PharmaScan 70/16 system with a 23-mm diameter birdcage $\mathrm{Tx} / \mathrm{Rx}$ coil specifically designed for the mouse brain (Bruker Biospin, Ettlingen, Germany) using standard operational software (Paravision 6.0.1). We acquired triplot images to ensure proper sample positioning with respect to the magnet isocenter. Shim gradients were adjusted using the MAPSHIM protocol with an ellipsoid reference volume covering the whole brain. We obtained diffusion-weighted images using a standard spin-echo 2D pulse sequence using the following parameters: repetition time $=4,158 \mathrm{~ms}$, echo time $=42 \mathrm{~ms}$, field of view $=15 \times 12 \mathrm{~mm}^{2}$, matrix size $=100 \times 80$, in-plane resolution $=0.15 \times 0.15 \mathrm{~mm}^{2}$, number of slices $=50$, slice thickness $=0.3 \mathrm{~mm}$, diffusion gradient duration $=6 \mathrm{~ms}$, diffusion gradient separation $=30 \mathrm{~ms}, \mathrm{~b}$-value $=2,000$ $\mathrm{s} / \mathrm{mm}^{2}$, number of diffusion directions $=30$, number of b0 images $=1$, effective spectral bandwidth $=30 \mathrm{kHz}$, fat suppression $=$ on, and number of averages $=10$. The diffusionweighted images was acquired at $22^{\circ} \mathrm{C}-26^{\circ} \mathrm{C}$ for $22 \mathrm{~h}$ per mouse.

Diffusion-weighted image analysis: Acquired images were processed using the Advanced Normalization Tools (http://stnava.github.io/ANTs/) and FMRIB Software Library (FSL) software packages (https://fsl.fmrib.ox.ac.uk/fsl/fslwiki). The procedure for image processing was as follows: (i) Image reconstruction was performed using Paravision software and converted to the NIfTI format using "DSI Studio" software (http://dsi-studio.labsolver.org/); (ii) eddy-current induced distortions were corrected using the eddy_correct tool of FSL; (iii) individual reference b0 images were manually skull-stripped using ITK-SNAP software (http://www.itksnap.org); (iv) other subject b0 
493 images were registered to the reference image and skull-stripped; (v) scalar images

494 were reconstructed using the DTIFIT tool of FSL; (vi) b0 and scalar images were

495 manually rotated and translated to ensure that the coordinate origins occupied the 496 anterior commissure midpoint to roughly match the standard reference space; (vii) b0

497 and scalar images were resampled onto an 0.15-mm isotropic voxel; (viii) the Minimum

498 Deformation Template (MDT) space was constructed using all subject b0 and scalar

499 images, including FA, AD, MD, and RD images; (ix) b0 and scalar images were warped

500 to the MDT space; $(x)$ the mean b0 image was computed, manually skull-stripped, and

501 registered to the atlas image; and (xi) the mean FA, $A D, M D$, and $R D$ values in each

502 structure were computed and statistically analyzed.

Black-Gold II staining

505 Two-to three-month-old female mice were perfused with saline and $4 \%$

paraformaldehyde as per the standard protocol (28). We mounted a pair of free-floating

40- $\mu \mathrm{m}$ thick coronal sections from a +/+ mouse and a +/- littermate as the upper and

508 lower rows, respectively, on the same slides (3-4 section pairs per slide) to control for

509 cross-slide staining variations. Care was taken to mount a section pair with similar

510 coordinates from $+/+$ and $+/$ - mice on the upper and lower rows of a slide.

512 The degree of myelination was examined using Black-Gold II staining (85). Black-Gold II

513 is an aurohalophosphate complex that directly stains myelin within the CNS. Black-Gold

514 II and sodium thiosulfate solution (AG105, Millipore, Temecula, CA) were heated to

$51560^{\circ} \mathrm{C}$. Slide-mounted sections were rehydrated in filtered water, transferred to pre-

516 warmed Black-Gold II solution, and incubated at $60^{\circ} \mathrm{C}$ for $>12 \mathrm{~min}$. Subsequently, the

517 sections were rinsed in filtered water twice for 2 min each, transferred to sodium 
518 thiosulfate solution, and incubated for $3 \mathrm{~min}$ at $60^{\circ} \mathrm{C}$. Finally, the sections were rinsed

519 three times in filtered water for 2 min each and cover-slipped.

521 We semi-quantified gold-staining within the fimbria and corpus callosum using a 522 Keyence microscope and its controller (BZ-X810 and BZ-X800E). Under a light microscope, staining blocked light penetration through the sections and registered as 524 less bright. This property was employed for semi-quantitative analysis. of which were defined as anterior and posterior areas of the two regions for analysis.

The fimbria and corpus callosum regions were delineated as targets (see Fig. S6). We divided the fimbria and corpus callosum at Bregma $-1.30 \mathrm{~mm}$, the anterior and posterior

The Keyence software yields brightness $(B)$ values as integration values within a range of threshold values from 0 to 255 . The threshold value acts as a filter and determines the level of light that is allowed to penetrate through a section. We observed that sampling pixels gradually saturated areas where tissues exist up to a threshold unit value of 137 , above which pixels started to appear non-specifically in areas devoid of tissue (e.g., blood vessels and between-tissue gaps). Thus, signals are maximally detected without false positive signals at this threshold value. This threshold was consistently used in the analysis of staining signals. Since B represents the sum of all integration values within the delineated area, it is affected by the size of the area. Because the target area size varied from section to section, we computed $B$ per area $(A)$ unit of the target (t) region (i.e., tB/A) in the fimbria and corpus callosum (S-Table 1, Step 1). 
542 Although we minimized slide-to-slide variations in staining intensity by dipping a set of

543 slides in the same Black-Gold II solution, there was still variation. This was observed as

544 varying non-specific baseline staining across sections. To correct for this variation, we

545 adjusted the tB/A value based on the degree of non-specific staining. We chose a 250

$546 \mu \mathrm{m} \times 250 \mu \mathrm{m}$ cortical area above the target fimbria and corpus callosum, where gold-

547 labeling was negligible. We defined it as a negative control (nc) area where B/A values

548 represent non-specific staining (S-Table 1, Step 2). The threshold unit for genuine tissue

549 signals was 255 in the cortex, above which signals started to appear in areas with no

550 tissue. We next chose a section with the maximum negative control $B / A$ (max ncB/A)

551 value and converted all $n c B / A$ values to ratios $(R=(\max n c B / A) /(n c B / A)$, S-Table 1, Step

$5523)$.

Next, the tB/A value was multiplied by the $R$ value, such that an under-estimated brightness signal due to non-specific staining (i.e., low B/A value) was rectified proportionally to the relative degree of non-specific staining $\left(\mathrm{tB} / \mathrm{A}^{\mathrm{adj}}=(\mathrm{tB} / \mathrm{A})^{\star} \mathrm{R}, \mathrm{S}-\mathrm{Table} \mathbf{1}\right.$, Step 4).

As staining intensity is inversely proportional to the $\mathrm{tB} / \mathrm{A}^{\text {adj }}$ value, greater gold staining 560 indicates that less light penetrates a section. The inverse value of $t B / A^{\text {adj }}$ was calculated $561\left(1 /\left(\mathrm{tB} / \mathrm{A}^{\mathrm{adj}}\right), \mathrm{S}-\mathrm{Table} 1\right.$, Step 5$)$ and multiplied by $10^{3}$ to express values above the 562 decimal point.

\section{EM analyses}

565 Two- to three-month-old male mice were anesthetized using $4-5 \%$ isoflurane in a 
vaporizer. The animals were intracardially perfused with $100 \mathrm{~mL}$ of $0.9 \%$ physiological saline followed by approximately $250 \mathrm{~mL}$ of freshly prepared $0.1 \mathrm{M}$ sodium cacodylate buffer (pH 7.4; Electron Microscopy Sciences cat \#11653), which contained 2.5\% glutaraldehyde (Electron Microscopy Sciences cat \#16320) and 2.5\% PFA (Electron Microscopy Sciences cat \#19202). Next, the brains were split into two hemispheres and post-fixed in fixative at $4^{\circ} \mathrm{C}$ for 2 weeks. Samples from the target areas (fimbria and corpus callosum) were obtained using a vibratome and placed in $0.1 \mathrm{M}$ sodium cacodylate buffer overnight. The tissues were then rinsed three times for 10 min each in $0.1 \mathrm{M}$ cacodylate buffer to remove aldehydes, following which they were placed in a mixture $(500 \mu \mathrm{L})$ of $2 \% \mathrm{OsO}_{4}$ (Electron Microscopy Sciences, cat\#19150) and $0.1 \mathrm{M}$ sodium cacodylate buffer for $1 \mathrm{~h}$. The tissue samples were agitated and shaken, rinsed ( $3 \times 5 \min 0.1 \mathrm{M} \mathrm{Na}$ cacodylate), and dehydrated twice in a series of ice-cold ethanol solutions for 5 min each (30\% ethanol; $50 \%$ ethanol; $70 \%$ ethanol; $90 \%$ ethanol; $95 \%$ ethanol) and three times in $100 \%$ ethanol for 10 min. Next, the tissues were rinsed twice in propylene oxide for 30 min each (Polysciences, Inc., cat\# 00236-1). This was followed by incubation on a mixer at room temperature overnight in an approximately $1 \mathrm{~mL}$ mixture of 1 part propylene oxide and 1 part Polybed resin solution (Poly/Bed® 812 Embedding Media, Polysciences, Inc., cat\# 08791-500; Dodecenylsuccinic anhydride (DDSA, Polysciences Inc., cat\# 00563-450), nadic methyl anhydride (NMA, Polysciences Inc., cat\# 00886-500), and 2,4,6-Tris-(dimethylaminomethyl)phenol (DMP30, Polysciences, Inc., cat\# 00553-100). On the next day, the Polybed resin/propylene oxide solution was removed, and the tissues were incubated for $24 \mathrm{~h}$ in $100 \%$ Polybed solution on a mixer at room temperature. Tissues were removed from the Polybed resin and placed in a mold, following which fresh polyresin was added. After the resulting bubbles had disappeared, the tissues in the mold were incubated at $55^{\circ} \mathrm{C}$ for $36 \mathrm{~h}$. 
592 Subsequently, they were processed at the Electron Microscopy Laboratory of the UT

593 Health Science Center in San Antonio using the in-house procedure (86). The tissues

594 were cut at $1 \mu \mathrm{m}$ and stained using $0.1 \%$ toluidine blue/0,0.1\% methylene blue/0, and

$595 \quad 0.1 \%$ azure II in $1 \%$ sodium borate buffer. Next, 100-nm thick sections were cut and

596 collected on 300 hexagonal mesh copper grids (Electron Microscopy Sciences, cat \#

$597 \mathrm{~T} 300 \mathrm{H}-\mathrm{Cu})$. In each set of five grids, three were stained, and two were left unstained.

598 Staining was performed using 5\% uranyl acetate in 50\% methanol and Reynold's lead

599 citrate (87). We measured the diameters of myelinated axons and their axon portions.

\section{qRT-PCR}

We used 2-3 month-old female $T b x 1+/+$ and +/- littermates. Total RNA was extracted

from brain regions of adult mice using an RNeasy Plus Mini Kit (Cat\#74134, Qiagen,

604 Germantown, USA), in accordance with the manufacturer's instructions. cDNA was

synthesized from total RNA using SuperScript IV VILO master mix (Cat\# 11766050,

606 Invitrogen, Carlsbad, USA). Quantitative PCR reactions were performed in triplicate on

607 QuantStudio 6 Flex Real-Time PCR Systems (Cat\#4485694, Applied Biosystems,

608 Waltham, USA) using the TaqMan Fast Advanced Master Mix (Cat\#4444963, Applied

609 Biosystems, Waltham, USA). The Taqman probes are listed in the Supplementary

610 Material (Table S3). Data were analyzed using the $\Delta \Delta \mathrm{Ct}$ method and normalized to the

611 reference gene Cyc1. 
614 We used P21 +/+ $(n=9)$ and +/- mice $(n=5)$ chosen from five litters. Progenitor cells

were isolated from the lateral ventricular walls of both hemispheres. Two $1 \mathrm{~mm}$ slices were taken from each of both hemispheres, and tissues that include the subventricular zone were dissected. Each culture was prepared using tissue from a single mouse. The tissues were dissociated using a Neural Tissue Dissociation Kit (P) (130-092-628, Miltenyi Biotech $\mathrm{GmbH}$, Germany). We did not purify neural progenitor cells with antibodies; thus, our cells contained different types of proliferating progenitor cells that generate neurons and oligodendrocytes. The cells were cultured in a medium (DMEM/F12 [11320-033, Gibco, CA, USA]) supplemented with N2 (17502048, Gibco), B27 (17504044, Gibco), epidermal growth factor (EGF) (20 ng/ml) (AF100-15, Peprotech, NJ, USA), and fibroblast growth factor 2 (FGF2) $(10 \mathrm{ng} / \mathrm{ml})(100-10 \mathrm{~B}$, Peprotech). After two to three passages, the cells were dissociated from the spheres and seeded on a Matrigel (356234, BD Biosciences, Bedford MA, USA)-coated slide chamber (154534, Nunc, NY, USA). To promote differentiation, the cells were cultured for 4 days in medium supplemented with $5 \%$ fetal calf serum. Next, the cells were fixed using 4\% PFA for 15 min and processed for immunofluorescence staining, using a purified mouse monoclonal O-4 antibody (1:50, MAB345, Millipore, MA, USA) for $12 \mathrm{~h}$ at $4^{\circ} \mathrm{C}$ after blocking for $30 \mathrm{~min}$ at room temperature with $5 \%$ donkey serum $(\mathrm{S} 30-100 \mathrm{ml}$, Millipore, MA, USA). Subsequently, the cells were incubated for $30 \mathrm{~min}$ at room temperature with Goat anti-Mouse IgM (Heavy Chain) Secondary Antibody, Alexa Fluor 647 (1:1000, A21238, Molecular Probes, OR USA). Nucleus staining was performed using 4',6-diamidino-2-phenylindole (DAPI) (3 mM, D3571, Molecular Probes). Cells were counted from four randomly selected fields per culture under a confocal microscope (TCS SP8, Leica, Germany), and the average score was obtained. 


\section{Behavioral analysis}

The mice were tested during the light phase between $10 \mathrm{AM}$ and 5 PM.

Morris water maze. Separate groups of 2-month-old male mice were used for the hidden and visible platform versions of the Morris water maze test. The water tank (103 cm in diameter; 914 Ix) contained white Prang® (Dixon Ticonderoga ${ }^{\circledR}$ ) Ready-to-Use Paint ( Item \#: 738062, Model \#: 21609/21949, Staples) mixed in water $\left(24 \pm 2^{\circ} \mathrm{C}\right)$. A circular platform (10 cm in diameter) was submerged $1 \mathrm{~cm}$ below the surface in the middle of one quadrant. Cues were placed on the wall $40 \mathrm{~cm}$ from the tank edge. The water was changed after testing on days 3 and 5 .

The hidden platform version involved 10 sessions conducted over 5 days (two daily sessions at intervals of 2-4 hours). Each session included four 60 -s trials conducted at 15-min intervals. The platform location remained constant (Quadrant 4); however, the entry points were semi-randomly changed across the trials. Before the fourth day of the hidden platform training, we performed a 60 -s probe trial for which the platform was removed. The entry point for the probe trials was the quadrant opposite to the target quadrant. An additional probe trial was conducted $72 \mathrm{~h}$ after the fifth day of hiddenplatform training.

The cued platform version involved six sessions conducted over 3 days (two daily sessions at intervals of $2-4 \mathrm{~h}$ with each session having two 60 -s trials at $15-\mathrm{min}$ intervals). The platform was marked using a flag placed above the water surface and visible to the mice. The platform locations were randomly assigned to each trial. The mice were placed in the maze from four equally spaced points along the pool perimeter, and the entry-point sequence was randomly chosen. For each placement, the animals 
664 were placed facing the sidewalls. The sequence of four start positions (north, south, 665 east, and west) varied across the trials.

671 stuffed with a dry paper towel.

Attentional set shifting: This test was performed using a procedure optimized for mice (59), with a slight modification. Two- to three-month-old male mice were individually housed and food-deprived to reduce the bodyweight to $85 \%$ of the ad libitum feeding weight, and this bodyweight was maintained throughout the testing period.

The mice were taken to the test room $1 \mathrm{~h}$ before the start of the training session. A single bowl containing 1/2 of a Honey Nut Cheerio buried in one medium stimulus sprinkled with an odor stimulus was placed in the home cage. This training used all possible combinations of exemplars of both dimensions (i.e., odor and medium) for subsequent use in the eight phases of attentional set shifting. The mice completed four daily trials, each involving a unique combination of medium and odor stimuli. The bowl was immediately removed from the home cage after the mouse had dug up the food pellet and eaten it. Each trial lasted approximately 1-2 min. After completing the daily training trials, the mouse was placed in a new home cage with fresh bedding. 
688 Next, we conducted a one-day habituation session in the attentional set-shifting

689 apparatus (outer dimensions: height $(\mathrm{H}), 15 \mathrm{~cm} \times$ width $(\mathrm{W}), 19.2 \mathrm{~cm} \times$ length (L), 49.2

690 cm; inner dimensions: H, $14.4 \mathrm{~cm} \times$ W, $18.3 \mathrm{~cm} \mathrm{x} \mathrm{L,} 48.3 \mathrm{~cm}$; 914 lux). The apparatus

691 was divided into two goal compartments (W, $9 \mathrm{~cm} \times \mathrm{L}, 14 \mathrm{~cm}$ each) and one start

692 compartment (W, $18.3 \mathrm{~cm}$ x L, $33.9 \mathrm{~cm})$ using 4.8-mm-thick walls. The mouse explored

693 the apparatus arena, which included a plastic weigh boat containing water in the start

694 compartment. The two goal compartments lacked bowls. After 3 minutes, the partition

695 door was placed to confine the mouse to the start compartment. After another 3 minutes,

696 the door was removed to allow the mouse to freely explore all three compartments. The

697 two 3-min sessions were repeated five times.

699 On the next day, training began in the attentional set-shifting session apparatus. The

water tray remained in the starting compartment during testing and initial re-training. The

701 two bowls in the goal compartments contained two medium stimuli (e.g., alpha dri and

702 paper chips) without odor stimuli; moreover, they were both baited using food. Both

703 media were used for the subsequent SD sessions. The partition door was placed to

704 confine the mouse to the start compartment. Care was taken to remove the door when

the mouse was not sniffing or facing it. Initially, the mice underwent four re-training trials

to retrieve the food from the bowl. The positions of both medium-containing bowls were

randomized in each trial. We placed an eighth of a Honey Nut Cheerio on top of (trial 1),

half-buried within (trial 2), slightly covered by (trial 3), and completely buried within (trial

4) the media. Each trial ended when the mouse had eaten food from both bowls.

711 Subsequently, the mice underwent a series of discrimination tests. Initially, each mouse

712 was placed in the start compartment with a partition door. The two goal compartments 
713 contained one baited bowl (an eighth of a Cheerio piece completely buried in the

714 medium) and one un-baited bowl; moreover, the position of the baited bowl was

715 randomized across the trials. The partition door was then lifted. Each trial ended when

716 the mouse had made a correct choice and had eaten the reward. If the mouse dug into

717 the un-baited bowl, it was removed after the mouse had spontaneously left the un-baited

718 compartment. A time-out was given if the mouse did not dig in any bowl for 3 min, which

719 involved removal of the bowl from the test arena and subsequent resumption of the trial

720 using a different medium/odor pair. In case of three consecutive time-outs, the testing

721 was ended and resumed the next day. Each of the eight phases ended when the mouse

722 had made eight consecutive correct choices or after 50 trials per day, whichever came

723 first. If a mouse made eight consecutive correct choices within 50 trials, a new phase

724 was administered the next day. After each test trial and when changing mice, the arena

725 and bowls were wiped using $70 \%$ ethanol.

727 The attentional set-shifting phases were as follows (Tables S4 and S5). For the SD

728 phase, there were two choices for the two relevant dimensions. The compound

729 discrimination (CD) phase was similar to the SD phase, except that a new correct

730 compound (O1\&M1 and O1\&M2) was added. The IDS IV phase involved CD using two

731 novel exemplars from relevant and irrelevant dimensions for each IDS with the same

732 relevance. The IDS IV rev phase involved the same exemplar set as the IDS IV phase,

733 except that the correct choice within the relevant dimension was reversed. The

734 extradimensional shifting (EDS) phase involved novel CD, except that the correct choice

735 was an exemplar of the previously irrelevant dimension up to IDS-IV rev. The order of

736 discrimination and exemplars was similar for all mice. The exemplar choice and correct

737 bowl position were pre-determined using a random number table. 
739 The standard mouse SD procedure uses O1 plus M1 and O2 plus M1 (59). Our modified

$740 \mathrm{SD}$ procedure used a combination of two dimensions (O1 plus $\mathrm{M} 1$ as the correct

741 discriminants and $\mathrm{O} 2$ plus M2 as the incorrect discriminants). Our pilot study indicated

742 that, compared with +/+ mice, +/- mice exhibited a longer latency to complete this

743 modified task.

We determined the number of trials taken to reach eight consecutive correct choices and the latency to complete a trial from the trial start to the time point when the mice began 747 eating the food pellet.

Olfactory responses to social and non-social cues. This test was conducted in a test cage

$(\mathrm{L}, 28.5 \mathrm{~cm} \times \mathrm{W}, 17.5 \mathrm{~cm} \times \mathrm{H}, 12.5 \mathrm{~cm})$ that had been divided into a $19.5 \mathrm{~cm}$-long compartment and a $9 \mathrm{~cm}$-long compartment using a partition wall with a $5 \mathrm{~cm}(\mathrm{H}) \times 5 \mathrm{~cm}$ (W) opening; 430 lux. The test was conducted as previously described (24), with slight modifications. First, 2-month-old male mice were habituated to the apparatus for $15 \mathrm{~min}$. A filter paper scented with a test odor was placed in a 1-ml Eppendorf tube containing small holes in the cap. Odors were sequentially tested as follows: water, almond, banana, urine from one non-littermate $\mathrm{C} 57 \mathrm{BL} / 6 \mathrm{~J}$ male (NL1), urine from another non-littermate C57BL/6J male (NL2), urine from the first C57BL/6N mouse (NL1), urine from a nonlittermate male +/- mouse $(\mathrm{HT})$, urine from the dam $(\mathrm{rm})$, urine from another litter's mother (am), and urine from a non-littermate virgin female C57BL/6J mouse (v). We measured sniffing of the tube containing odorant-soaked filter paper during the 2-min trials. The mice underwent three 2-min trials for each odorant with an inter-trial interval of approximately $10 \mathrm{~s}$; moreover, there was a 10-s interval between the three-trial session of one odorant and that of another. Urine was collected before testing and frozen at $-20^{\circ} \mathrm{C}$ until the test 
764 day. An Eppendorf tube with seven holes (one in the middle and six surrounding) in the

765 cap was used for each trial. The tube was attached to the cage wall using Velcro. The filter

766 paper (Whatman, \#3698-325, Maidstone England) was soaked in $10 \mu \mathrm{l}$ of each odorant.

767 During habituation, we placed dry filter paper in the tube.

769 Statistical analysis

770 We used GraphPad Prism 8.3.0 (GraphPad Software, San Diego, CA) and

771 IBM SPSS Statistics 26.0.0.0, IBM, Armonk, NY). Among-group and between-group

772 comparisons of the data were performed using analyses of variance and Student's t-test,

773 respectively. Normality and variance homogeneity of the data were evaluated using the

774 Shapiro-Wilk test and Levene's homogeneity of variance test, respectively. In case either

775 assumption was violated, data were analyzed using a generalized linear mixed model or

776 Mann-Whitney U-tests and Wilcoxon non-parametric tests for unpaired and paired data,

777 respectively. The number of cases was analyzed using the $\chi^{2}$ test. The minimum

778 significance level was set at 5\%. In case multiple tests were applied for a data set, the

779 significance level was adjusted using the Benjamini-Hochberg correction, with a false

780 discovery rate of $5 \%$. 


\section{References}

1. D. Malhotra, J. Sebat, CNVs: harbingers of a rare variant revolution in psychiatric genetics. Cell 148, 1223-1241 (2012).

2. G. Kirov, E. Rees, J. T. Walters, V. Escott-Price, L. Georgieva, A. L. Richards, K. D. Chambert, G. Davies, S. E. Legge, J. L. Moran, S. A. McCarroll, M. C. O'Donovan, M. J. Owen, The Penetrance of Copy Number Variations for Schizophrenia and Developmental Delay. Biol. Psychiatry 75, 378-385 (2013).

3. H. Stefansson, A. Meyer-Lindenberg, S. Steinberg, B. Magnusdottir, K. Morgen, S. Arnarsdottir, G. Bjornsdottir, G. B. Walters, G. A. Jonsdottir, O. M. Doyle, H. Tost, O. Grimm, S. Kristjansdottir, H. Snorrason, S. R. Davidsdottir, L. J. Gudmundsson, G. F. Jonsson, B. Stefansdottir, I. Helgadottir, M. Haraldsson, B. Jonsdottir, J. H. Thygesen, A. J. Schwarz, M. Didriksen, T. B. Stensbol, M. Brammer, S. Kapur, J. G. Halldorsson, S. Hreidarsson, E. Saemundsen, E. Sigurdsson, K. Stefansson, CNVs conferring risk of autism or schizophrenia affect cognition in controls. Nature 505, 361-366 (2014).

4. F. K. Satterstrom, J. A. Kosmicki, J. Wang, M. S. Breen, S. De Rubeis, J. Y. An, M. Peng, R. Collins, J. Grove, L. Klei, C. Stevens, J. Reichert, M. S. Mulhern, M. Artomov, S. Gerges, B. Sheppard, X. Xu, A. Bhaduri, U. Norman, H. Brand, G. Schwartz, R. Nguyen, E. E. Guerrero, C. Dias, C. Autism Sequencing, P.-B. C. i, C. Betancur, E. H. Cook, L. Gallagher, M. Gill, J. S. Sutcliffe, A. Thurm, M. E. Zwick, A. D. Borglum, M. W. State, A. E. Cicek, M. E. Talkowski, D. J. Cutler, B. Devlin, S. J. Sanders, K. Roeder, M. J. Daly, J. D. Buxbaum, Large-Scale Exome Sequencing Study Implicates Both Developmental and Functional Changes in the Neurobiology of Autism. Cell 180, 568-584 e523 (2020).

5. S. J. Sanders, X. He, A. J. Willsey, A. G. Ercan-Sencicek, K. E. Samocha, A. E. Cicek, M. T. Murtha, V. H. Bal, S. L. Bishop, S. Dong, A. P. Goldberg, C. Jinlu, J. F. Keaney, III, L. Klei, J. D. Mandell, D. Moreno-De-Luca, C. S. Poultney, E. B. Robinson, L. Smith, T. Solli-Nowlan, M. Y. Su, N. A. Teran, M. F. Walker, D. M. Werling, A. L. Beaudet, R. M. Cantor, E. Fombonne, D. H. Geschwind, D. E. Grice, C. Lord, J. K. Lowe, S. M. Mane, D. M. Martin, E. M. Morrow, M. E. Talkowski, J. S. Sutcliffe, C. A. Walsh, T. W. Yu, D. H. Ledbetter, C. L. Martin, E. H. Cook, J. D. Buxbaum, M. J. Daly, B. Devlin, K. Roeder, S. MW, Insights into Autism Spectrum Disorder Genomic Architecture and Biology from 71 Risk Loci. Neuron 87, 1215-1233 (2015).

6. I. Mitra, B. Huang, N. Mousavi, N. Ma, M. Lamkin, R. Yanicky, S. Shleizer-Burko, K. E. Lohmueller, M. Gymrek, Patterns of de novo tandem repeat mutations and their role in autism. Nature 589, 246-250 (2021).

7. R. J. Shprintzen, R. Goldberg, K. J. Golding-Kushner, R. W. Marion, Late-onset psychosis in the velo-cardio-facial syndrome. American Journal of Medical Genetics 42, 141-142 (1992).

8. J. Zinkstok, E. Boot, A. S. Bassett, N. Hiroi, N. J. Butcher, C. Vingerhoets, J. A. S. Vorstman, T. A. M. J. van Amelsvoort, The 22q11.2 deletion syndrome from a neurobiological perspective. Lancet Psychiatry 6, 951-960. (2019).

9. R. E. Gur, J. J. Yi, D. M. Donald-McGinn, S. X. Tang, M. E. Calkins, D. Whinna, M. C. Souders, A. Savitt, E. H. Zackai, P. J. Moberg, B. S. Emanuel, R. C. Gur, Neurocognitive development in 22q11.2 deletion syndrome: comparison with youth having developmental delay and medical comorbidities. Mol. Psychiatry 19, 1205-1211 (2014). 
10. K. M. Kendall, M. Bracher-Smith, H. Fitzpatrick, A. Lynham, E. Rees, V. Escott-Price, M. J. Owen, M. C. O'Donovan, J. T. R. Walters, G. Kirov, Cognitive performance and functional outcomes of carriers of pathogenic copy number variants: analysis of the UK Biobank. Br J Psychiatry 214, 297-304 (2019).

11. S. Chawner, M. J. Owen, P. Holmans, F. L. Raymond, D. Skuse, J. Hall, M. B. M. van den Bree, Genotype-phenotype associations in children with copy number variants associated with high neuropsychiatric risk in the UK (IMAGINE-ID): a case-control cohort study. Lancet Psychiatry 6, 493-505 (2019).

12. R. C. Gur, M. E. Calkins, T. D. Satterthwaite, K. Ruparel, W. B. Bilker, T. M. Moore, A. P. Savitt, H. Hakonarson, R. E. Gur, Neurocognitive growth charting in psychosis spectrum youths. JAMA Psychiatry 71, 366-374 (2014).

13. J. A. Vorstman, E. J. Breetvelt, S. N. Duijff, S. Eliez, M. Schneider, M. Jalbrzikowski, M. Armando, S. Vicari, V. Shashi, S. R. Hooper, E. W. Chow, W. L. Fung, N. J. Butcher, D. A. Young, D. M. McDonald-McGinn, A. Vogels, T. van Amelsvoort, D. Gothelf, R. Weinberger, A. Weizman, P. W. Klaassen, S. Koops, W. R. Kates, K. M. Antshel, T. J. Simon, O. Y. Ousley, A. Swillen, R. E. Gur, C. E. Bearden, R. S. Kahn, A. S. Bassett, B. International Consortium on, S. Behavior in 22q11.2 Deletion, Cognitive decline preceding the onset of psychosis in patients with 22q11.2 deletion syndrome. JAMA Psychiatry 72, 377-385 (2015).

14. P. M. Thompson, N. Jahanshad, C. R. K. Ching, L. E. Salminen, S. I. Thomopoulos, J. Bright, B. T. Baune, S. Bertolin, J. Bralten, W. B. Bruin, R. Bulow, J. Chen, Y. Chye, U. Dannlowski, C. G. F. de Kovel, G. Donohoe, L. T. Eyler, S. V. Faraone, P. Favre, C. A. Filippi, T. Frodl, D. Garijo, Y. Gil, H. J. Grabe, K. L. Grasby, T. Hajek, L. K. M. Han, S. N. Hatton, K. Hilbert, T. C. Ho, L. Holleran, G. Homuth, N. Hosten, J. Houenou, I. Ivanov, T. Jia, S. Kelly, M. Klein, J. S. Kwon, M. A. Laansma, J. Leerssen, U. Lueken, A. Nunes, J. O. Neill, N. Opel, F. Piras, F. Piras, M. C. Postema, E. Pozzi, N. Shatokhina, C. Soriano-Mas, G. Spalletta, D. Sun, A. Teumer, A. K. Tilot, L. Tozzi, C. van der Merwe, E. J. W. Van Someren, G. A. van Wingen, H. Volzke, E. Walton, L. Wang, A. M. Winkler, K. Wittfeld, M. J. Wright, J. Y. Yun, G. Zhang, Y. Zhang-James, B. M. Adhikari, I. Agartz, M. Aghajani, A. Aleman, R. R. Althoff, A. Altmann, O. A. Andreassen, D. A. Baron, B. L. Bartnik-Olson, J. Marie Bas-Hoogendam, A. R. Baskin-Sommers, C. E. Bearden, L. A. Berner, P. S. W. Boedhoe, R. M. Brouwer, J. K. Buitelaar, K. Caeyenberghs, C. A. M. Cecil, R. A. Cohen, J. H. Cole, P. J. Conrod, S. A. De Brito, S. M. C. de Zwarte, E. L. Dennis, S. Desrivieres, D. Dima, S. Ehrlich, C. Esopenko, G. Fairchild, S. E. Fisher, J. P. Fouche, C. Francks, S. Frangou, B. Franke, H. P. Garavan, D. C. Glahn, N. A. Groenewold, T. P. Gurholt, B. A. Gutman, T. Hahn, I. H. Harding, D. Hernaus, D. P. Hibar, F. G. Hillary, M. Hoogman, H. E. Hulshoff Pol, M. Jalbrzikowski, G. A. Karkashadze, E. T. Klapwijk, R. C. Knickmeyer, P. Kochunov, I. K. Koerte, X. Z. Kong, S. L. Liew, A. P. Lin, M. W. Logue, E. Luders, F. Macciardi, S. Mackey, A. R. Mayer, C. R. McDonald, A. B. McMahon, S. E. Medland, G. Modinos, R. A. Morey, S. C. Mueller, P. Mukherjee, L. Namazova-Baranova, T. M. Nir, A. Olsen, P. Paschou, D. S. Pine, F. Pizzagalli, M. E. Renteria, J. D. Rohrer, P. G. Samann, L. Schmaal, G. Schumann, M. S. Shiroishi, S. M. Sisodiya, D. J. A. Smit, I. E. Sonderby, D. J. Stein, J. L. Stein, M. Tahmasian, D. F. Tate, J. A. Turner, O. A. van den Heuvel, N. J. A. van der Wee, Y. D. van der Werf, T. G. M. van Erp, N. E. M. van Haren, D. van Rooij, L. S. van Velzen, I. M. Veer, D. J. Veltman, J. E. Villalon-Reina, H. Walter, C. D. Whelan, E. A. Wilde, M. Zarei, V. Zelman, E. Consortium, ENIGMA and global neuroscience: A decade of largescale studies of the brain in health and disease across more than 40 countries. Transl Psychiatry 10, 100 (2020). 
15. J. E. Villalon-Reina, K. Martinez, X. Qu, C. R. K. Ching, T. M. Nir, D. Kothapalli, C. Corbin, D. Sun, A. Lin, J. K. Forsyth, L. Kushan, A. Vajdi, M. Jalbrzikowski, L. Hansen, R. K. Jonas, T. van Amelsvoort, G. Bakker, W. R. Kates, K. M. Antshel, W. Fremont, L. E. Campbell, K. L. McCabe, E. Daly, M. Gudbrandsen, C. M. Murphy, D. Murphy, M. Craig, B. Emanuel, D. M. McDonald-McGinn, J. A. S. Vorstman, A. M. Fiksinski, S. Koops, K. Ruparel, D. Roalf, R. E. Gur, J. Eric Schmitt, T. J. Simon, N. J. GoodrichHunsaker, C. A. Durdle, J. L. Doherty, A. C. Cunningham, M. van den Bree, D. E. J. Linden, M. Owen, H. Moss, S. Kelly, G. Donohoe, K. C. Murphy, C. Arango, N. Jahanshad, P. M. Thompson, C. E. Bearden, Altered white matter microstructure in 22q11.2 deletion syndrome: a multisite diffusion tensor imaging study. Mol Psychiatry 25, 2818-2831 (2020).

16. P. Kochunov, L. E. Hong, E. L. Dennis, R. A. Morey, D. F. Tate, E. A. Wilde, M. Logue, S. Kelly, G. Donohoe, P. Favre, J. Houenou, C. R. K. Ching, L. Holleran, O. A. Andreassen, L. S. van Velzen, L. Schmaal, J. E. Villalon-Reina, C. E. Bearden, F. Piras, G. Spalletta, O. A. van den Heuvel, D. J. Veltman, D. J. Stein, M. C. Ryan, Y. Tan, T. G. M. van Erp, J. A. Turner, L. Haddad, T. M. Nir, D. C. Glahn, P. M. Thompson, N. Jahanshad, ENIGMA-DTI: Translating reproducible white matter deficits into personalized vulnerability metrics in cross-diagnostic psychiatric research. Hum Brain Mapp, (2020).

17. W. Gong, S. Gottlieb, J. Collins, A. Blescia, H. Dietz, E. Goldmuntz, D. M. DonaldMcGinn, E. H. Zackai, B. S. Emanuel, D. A. Driscoll, M. L. Budarf, Mutation analysis of TBX1 in non-deleted patients with features of DGS/VCFS or isolated cardiovascular defects. J. Med. Genet 38, E45 (2001).

18. K. Hasegawa, H. Tanaka, Y. Higuchi, Y. Hayashi, K. Kobayashi, H. Tsukahara, Novel heterozygous mutation in TBX1 in an infant with hypocalcemic seizures. Clin Pediatr Endocrinol 27, 159-164 (2018).

19. T. Ogata, T. Niihori, N. Tanaka, M. Kawai, T. Nagashima, R. Funayama, K. Nakayama, S. Nakashima, F. Kato, M. Fukami, Y. Aoki, Y. Matsubara, TBX1 mutation identified by exome sequencing in a Japanese family with 22q11.2 deletion syndrome-like craniofacial features and hypocalcemia. PLoS. One 9, e91598 (2014).

20. R. Paylor, B. Glaser, A. Mupo, P. Ataliotis, C. Spencer, A. Sobotka, C. Sparks, C. H. Choi, J. Oghalai, S. Curran, K. C. Murphy, S. Monks, N. Williams, M. C. O'Donovan, M. J. Owen, P. J. Scambler, E. Lindsay, Tbx1 haploinsufficiency is linked to behavioral disorders in mice and humans: implications for 22q11 deletion syndrome. Proc. Natl. Acad. Sci. U. S. A 103, 7729-7734 (2006).

21. N. Hiroi, H. Zhu, M. Lee, B. Funke, M. Arai, M. Itokawa, R. Kucherlapati, B. Morrow, T. Sawamura, S. Agatsuma, A 200-kb region of human chromosome 22q11.2 confers antipsychotic-responsive behavioral abnormalities in mice. Proceedings of the National Academy of Sciences of the United States of America 102, 19132-19137 (2005).

22. G. Suzuki, K. M. Harper, T. Hiramoto, B. Funke, M. Lee, G. Kang, M. Buell, M. A. Geyer, R. Kucherlapati, B. Morrow, P. T. Mannisto, S. Agatsuma, N. Hiroi, Overexpression of a human chromosome 22q11.2 segment including TXNRD2, COMT and ARVCF developmentally affects incentive learning and working memory in mice. Human Molecular Genetics 18, 3914-3925 (2009).

23. G. Suzuki, K. M. Harper, T. Hiramoto, T. Sawamura, M. Lee, G. Kang, K. Tanigaki, M. Buell, M. A. Geyer, W. S. Trimble, S. Agatsuma, N. Hiroi, Sept5 deficiency exerts pleiotropic influence on affective behaviors and cognitive functions in mice. Human Molecular Genetics 18, 1652-1660 (2009). 
24. T. Hiramoto, G. Kang, G. Suzuki, Y. Satoh, R. Kucherlapati, Y. Watanabe, N. Hiroi, Tbx1: identification of a 22q11.2 gene as a risk factor for autism spectrum disorder in a mouse model. Hum Mol Genet 20, 4775-4785 (2011).

25. K. M. Harper, T. Hiramoto, K. Tanigaki, G. Kang, G. Suzuki, W. Trimble, N. Hiroi, Alterations of social interaction through genetic and environmental manipulation of the 22q11.2 gene Sept5 in the mouse brain. Human Molecular Genetics 21, 3489-3499 (2012).

26. N. Hiroi, T. Takahashi, A. Hishimoto, T. Izumi, S. Boku, T. Hiramoto, Copy Number Variation at 22q11.2: from rare variants to common mechanisms of developmental neuropsychiatric disorders. Mol. Psychiatry 18, 1153-1165 (2013).

27. T. Takahashi, S. Okabe, P. O. Broin, A. Nishi, K. Ye, M. V. Beckert, T. Izumi, A. Machida, G. Kang, S. Abe, J. L. Pena, A. Golden, T. Kikusui, N. Hiroi, Structure and function of neonatal social communication in a genetic mouse model of autism. Mol Psychiatry 21, 1208-1214 (2016).

28. S. Boku, T. Izumi, S. Abe, T. Takahashi, A. Nishi, H. Nomaru, Y. Naka, G. Kang, M. Nagashima, A. Hishimoto, S. Enomoto, G. Duran-Torres, K. Tanigaki, J. Zhang, K. Ye, S. Kato, P. T. Mannisto, K. Kobayashi, N. Hiroi, Copy number elevation of 22q11.2 genes arrests the developmental maturation of working memory capacity and adult neurogenesis. Molecular Psychiatry 23, 985-992 (2018).

29. N. Hiroi, T. Yamauchi, Modeling and Predicting Developmental Trajectories of Neuropsychiatric Dimensions Associated With Copy Number Variations. Int $J$ Neuropsychopharmacol 22, 488-500 (2019).

30. R. Kato, A. Machida, K. Nomoto, G. Kang, T. Hiramoto, K. Tanigaki, K. Mogi, N. Hiroi, T. Kikusui, Maternal approach behaviors toward neonatal calls are impaired by mother's experiences of raising pups with a risk gene variant for autism. Dev Psychobiol 63, 108$113(2021)$.

31. Y. Ma, P. R. Hof, S. C. Grant, S. J. Blackband, R. Bennett, L. Slatest, M. D. McGuigan, $\mathrm{H}$. Benveniste, A three-dimensional digital atlas database of the adult C57BL/6J mouse brain by magnetic resonance microscopy. Neuroscience 135, 1203-1215 (2005).

32. A. Lazari, I. Lipp, Can MRI measure myelin? Systematic review, qualitative assessment, and meta-analysis of studies validating microstructural imaging with myelin histology. Neuroimage, 117744 (2021).

33. E. H. Chang, M. Argyelan, M. Aggarwal, T. S. Chandon, K. H. Karlsgodt, S. Mori, A. K. Malhotra, The role of myelination in measures of white matter integrity: Combination of diffusion tensor imaging and two-photon microscopy of CLARITY intact brains. Neuroimage 147, 253-261 (2017).

34. C. Sampaio-Baptista, A. A. Khrapitchev, S. Foxley, T. Schlagheck, J. Scholz, S. Jbabdi, G. C. DeLuca, K. L. Miller, A. Taylor, N. Thomas, J. Kleim, N. R. Sibson, D. Bannerman, H. Johansen-Berg, Motor skill learning induces changes in white matter microstructure and myelination. J Neurosci 33, 19499-19503 (2013).

35. J. M. Soares, P. Marques, V. Alves, N. Sousa, A hitchhiker's guide to diffusion tensor imaging. Front Neurosci 7, 31 (2013).

36. L. Schmued, J. Bowyer, M. Cozart, D. Heard, Z. Binienda, M. Paule, Introducing BlackGold II, a highly soluble gold phosphate complex with several unique advantages for the histochemical localization of myelin. Brain Res 1229, 210-217 (2008).

37. T. Chomiak, B. Hu, What is the optimal value of the g-ratio for myelinated fibers in the rat CNS? A theoretical approach. PLoS One 4, e7754 (2009).

38. N. Downes, P. Mullins, The development of myelin in the brain of the juvenile rat. Toxicol Pathol 42, 913-922 (2014). 
39. F. M. de Vrij, C. G. Bouwkamp, N. Gunhanlar, G. Shpak, B. Lendemeijer, M. Baghdadi, S. Gopalakrishna, M. Ghazvini, T. M. Li, M. Quadri, S. Olgiati, G. J. Breedveld, M. Coesmans, E. Mientjes, T. de Wit, F. W. Verheijen, H. B. Beverloo, D. Cohen, R. M. Kok, P. R. Bakker, A. Nijburg, A. T. Spijker, P. M. J. Haffmans, E. Hoencamp, V. Bergink, G. S. Consortium, J. A. Vorstman, T. Wu, L. M. Olde Loohuis, N. Amin, C. D. Langen, A. Hofman, W. J. Hoogendijk, C. M. van Duijn, M. A. Ikram, M. W. Vernooij, H. Tiemeier, A. G. Uitterlinden, Y. Elgersma, B. Distel, J. Gribnau, T. White, V. Bonifati, S. A. Kushner, Candidate CSPG4 mutations and induced pluripotent stem cell modeling implicate oligodendrocyte progenitor cell dysfunction in familial schizophrenia. $\mathrm{Mol}$ Psychiatry, (2018).

40. M. Fruttiger, L. Karlsson, A. C. Hall, A. Abramsson, A. R. Calver, H. Bostrom, K. Willetts, C. H. Bertold, J. K. Heath, C. Betsholtz, W. D. Richardson, Defective oligodendrocyte development and severe hypomyelination in PDGF-A knockout mice. Development 126, 457-467 (1999).

41. M. S. Meschkat, A.M.; Weil, M.-T.; Kusch, K.; Jahn, O.; Piepkorn, L.; Agüi-Gonzalez, P.; Phan, N.T.N;Ruhwedel, T.; Sadowski, B.; Rizzoli, S.O.; Werner, H.B.; Ehrenreich, H.; Nave, K.-A.; Möbius, W., White matter integrity requires continuous myelin synthesis at the inner tongue bioRxiv, (2020).

42. C. Readhead, B. Popko, N. Takahashi, H. D. Shine, R. A. Saavedra, R. L. Sidman, L. Hood, Expression of a myelin basic protein gene in transgenic shiverer mice: correction of the dysmyelinating phenotype. Cell 48, 703-712 (1987).

43. C. Delarasse, P. Daubas, L. T. Mars, C. Vizler, T. Litzenburger, A. Iglesias, J. Bauer, B. Della Gaspera, A. Schubart, L. Decker, D. Dimitri, G. Roussel, A. Dierich, S. Amor, A. Dautigny, R. Liblau, D. Pham-Dinh, Myelin/oligodendrocyte glycoprotein-deficient (MOG-deficient) mice reveal lack of immune tolerance to MOG in wild-type mice. J Clin Invest 112, 544-553 (2003).

44. A. Aguirre, V. Gallo, Postnatal neurogenesis and gliogenesis in the olfactory bulb from NG2-expressing progenitors of the subventricular zone. J Neurosci 24, 10530-10541 (2004).

45. E. L. Jackson, J. M. Garcia-Verdugo, S. Gil-Perotin, M. Roy, A. Quinones-Hinojosa, S. VandenBerg, A. Alvarez-Buylla, PDGFR alpha-positive B cells are neural stem cells in the adult SVZ that form glioma-like growths in response to increased PDGF signaling. Neuron 51, 187-199 (2006).

46. S. Belachew, R. Chittajallu, A. A. Aguirre, X. Yuan, M. Kirby, S. Anderson, V. Gallo, Postnatal NG2 proteoglycan-expressing progenitor cells are intrinsically multipotent and generate functional neurons. J Cell Biol 161, 169-186 (2003).

47. B. Menn, J. M. Garcia-Verdugo, C. Yaschine, O. Gonzalez-Perez, D. Rowitch, A. Alvarez-Buylla, Origin of oligodendrocytes in the subventricular zone of the adult brain. $J$ Neurosci 26, 7907-7918 (2006).

48. F. Ortega, S. Gascon, G. Masserdotti, A. Deshpande, C. Simon, J. Fischer, L. Dimou, D. Chichung Lie, T. Schroeder, B. Berninger, Oligodendrogliogenic and neurogenic adult subependymal zone neural stem cells constitute distinct lineages and exhibit differential responsiveness to Wnt signalling. Nat Cell Biol 15, 602-613 (2013).

49. D. K. Jones, M. Cercignani, Twenty-five pitfalls in the analysis of diffusion MRI data. NMR Biomed 23, 803-820 (2010).

50. M. G. Packard, J. L. McGaugh, Double dissociation of fornix and caudate nucleus lesions on acquisition of two water maze tasks: further evidence for multiple memory systems. Behav Neurosci 106, 439-446 (1992). 
51. D. K. Hannesson, R. W. Skelton, Recovery of spatial performance in the Morris water maze following bilateral transection of the fimbria/fornix in rats. Behav Brain Res 90, 3556 (1998).

52. J. J. Yi, R. Weinberger, T. M. Moore, M. E. Calkins, Y. Guri, D. M. McDonald-McGinn, E. H. Zackai, B. S. Emanuel, R. E. Gur, D. Gothelf, R. C. Gur, Performance on a computerized neurocognitive battery in 22q11.2 deletion syndrome: A comparison between US and Israeli cohorts. Brain Cogn 106, 33-41 (2016).

53. P. C. Goldenberg, M. E. Calkins, J. Richard, D. McDonald-McGinn, E. Zackai, N. Mitra, B. Emanuel, M. Devoto, K. Borgmann-Winter, C. Kohler, C. G. Conroy, R. C. Gur, R. E. Gur, Computerized neurocognitive profile in young people with 22q11.2 deletion syndrome compared to youths with schizophrenia and at-risk for psychosis. Am J Med Genet B Neuropsychiatr Genet 159B, 87-93 (2012).

54. C. E. Bearden, M. F. Woodin, P. P. Wang, E. Moss, D. Donald-McGinn, E. Zackai, B. Emannuel, T. D. Cannon, The neurocognitive phenotype of the 22q11.2 deletion syndrome: selective deficit in visual-spatial memory. J. Clin. Exp. Neuropsychol 23, 447$464(2001)$.

55. L. J. Drew, K. L. Stark, K. Fenelon, M. Karayiorgou, A. B. Macdermott, J. A. Gogos, Evidence for altered hippocampal function in a mouse model of the human 22q11.2 microdeletion. Mol Cell Neurosci 47, 293-305 (2011).

56. D. W. Meechan, H. L. Rutz, M. S. Fralish, T. M. Maynard, L. A. Rothblat, A. S. LaMantia, Cognitive ability is associated with altered medial frontal cortical circuits in the LgDel mouse model of 22q11.2DS. Cereb. Cortex [Epub ahead of print], 1143-1151 (2015).

57. A. Tripathi, M. Spedding, E. Schenker, M. Didriksen, A. Cressant, T. M. Jay, Cognitionand circuit-based dysfunction in a mouse model of 22q11.2 microdeletion syndrome: effects of stress. Transl Psychiatry 10, 41 (2020).

58. A. M. Owen, A. C. Roberts, C. E. Polkey, B. J. Sahakian, T. W. Robbins, Extradimensional versus intra-dimensional set shifting performance following frontal lobe excisions, temporal lobe excisions or amygdalo-hippocampectomy in man. Neuropsychologia 29, 993-1006 (1991).

59. G. B. Bissonette, G. J. Martins, T. M. Franz, E. S. Harper, G. Schoenbaum, E. M. Powell, Double dissociation of the effects of medial and orbital prefrontal cortical lesions on attentional and affective shifts in mice. J. Neurosci 28, 11124-11130 (2008).

60. J. M. Birrell, V. J. Brown, Medial frontal cortex mediates perceptual attentional set shifting in the rat. J. Neurosci 20, 4320-4324 (2000).

61. M. Jalbrzikowski, C. Carter, D. Senturk, C. Chow, J. M. Hopkins, M. F. Green, A. Galvan, T. D. Cannon, C. E. Bearden, Social cognition in 22q11.2 microdeletion syndrome: relevance to psychosis? Schizophr Res 142, 99-107 (2012).

62. Y. Deng, N. J. Goodrich-Hunsaker, M. Cabaral, D. G. Amaral, M. H. Buonocore, D. Harvey, K. Kalish, O. T. Carmichael, C. M. Schumann, A. Lee, R. F. Dougherty, L. M. Perry, B. A. Wandell, T. J. Simon, Disrupted fornix integrity in children with chromosome 22q11.2 deletion syndrome. Psychiatry Res 232, 106-114 (2015).

63. R. J. Franklin, C. ffrench-Constant, J. M. Edgar, K. J. Smith, Neuroprotection and repair in multiple sclerosis. Nat Rev Neurol 8, 624-634 (2012).

64. Y. Lee, B. M. Morrison, Y. Li, S. Lengacher, M. H. Farah, P. N. Hoffman, Y. Liu, A. Tsingalia, L. Jin, P. W. Zhang, L. Pellerin, P. J. Magistretti, J. D. Rothstein, Oligodendroglia metabolically support axons and contribute to neurodegeneration. Nature 487, 443-448 (2012).

65. A. S. Saab, I. D. Tzvetanova, K. A. Nave, The role of myelin and oligodendrocytes in axonal energy metabolism. Curr Opin Neurobiol 23, 1065-1072 (2013). 
66. J. L. Salzer, B. Zalc, Myelination. Curr Biol 26, R971-R975 (2016).

67. T. Yamauchi, G. Kang, N. Hiroi, Heterozygosity of murine Crkl does not recapitulate behavioral dimensions of human 22q11.2 hemizygosity Genes Brain and Behavior Online Version, e12719 (2020).

68. G. Koscielny, G. Yaikhom, V. Iyer, T. F. Meehan, H. Morgan, J. Atienza-Herrero, A. Blake, C. K. Chen, R. Easty, A. Di Fenza, T. Fiegel, M. Grifiths, A. Horne, N. A. Karp, N. Kurbatova, J. C. Mason, P. Matthews, D. J. Oakley, A. Qazi, J. Regnart, A. Retha, L. A. Santos, D. J. Sneddon, J. Warren, H. Westerberg, R. J. Wilson, D. G. Melvin, D. Smedley, S. D. Brown, P. Flicek, W. C. Skarnes, A. M. Mallon, H. Parkinson, The International Mouse Phenotyping Consortium Web Portal, a unified point of access for knockout mice and related phenotyping data. Nucleic Acids Res 42, D802-809 (2014).

69. M. Nakamura, K. Ye, M. Barbachan E Silva, T. Yamauchi, D. Hoeppner, A. Fayyazuddin, G. Kang, E. Yuda, M. Nagashima, S. Enomoto, T. Hiramoto, R. Sharp, I. Kaneko, K. Tajinda, M. Adachi, T. Mihara, S. Tokuno, M. Geyer, P. O’Broin, M. Matsumoto, N. Hiroi, Computational identification of variables in neonatal vocalizations predictive for post-pubertal social behaviors in a mouse model of 16p11.2 deletion. Molecular Psychiatry Online Published on April 15, 2021, (2021).

70. D. Koshiyama, M. Fukunaga, N. Okada, K. Morita, K. Nemoto, K. Usui, H. Yamamori, Y. Yasuda, M. Fujimoto, N. Kudo, H. Azechi, Y. Watanabe, N. Hashimoto, H. Narita, I. Kusumi, K. Ohi, T. Shimada, Y. Kataoka, M. Yamamoto, N. Ozaki, G. Okada, Y. Okamoto, K. Harada, K. Matsuo, H. Yamasue, O. Abe, R. Hashimoto, T. Takahashi, T. Hori, M. Nakataki, T. Onitsuka, L. Holleran, N. Jahanshad, T. G. M. van Erp, J. Turner, G. Donohoe, P. M. Thompson, K. Kasai, R. Hashimoto, Cocoro, White matter microstructural alterations across four major psychiatric disorders: mega-analysis study in 2937 individuals. Mol Psychiatry 25, 883-895 (2020).

71. S. Kelly, N. Jahanshad, A. Zalesky, P. Kochunov, I. Agartz, C. Alloza, O. A. Andreassen, C. Arango, N. Banaj, S. Bouix, C. A. Bousman, R. M. Brouwer, J. Bruggemann, J. Bustillo, W. Cahn, V. Calhoun, D. Cannon, V. Carr, S. Catts, J. Chen, J. X. Chen, X. Chen, C. Chiapponi, K. K. Cho, V. Ciullo, A. S. Corvin, B. Crespo-Facorro, V. Cropley, P. De Rossi, C. M. Diaz-Caneja, E. W. Dickie, S. Ehrlich, F. M. Fan, J. Faskowitz, H. Fatouros-Bergman, L. Flyckt, J. M. Ford, J. P. Fouche, M. Fukunaga, M. Gill, D. C. Glahn, R. Gollub, E. D. Goudzwaard, H. Guo, R. E. Gur, R. C. Gur, T. P. Gurholt, R. Hashimoto, S. N. Hatton, F. A. Henskens, D. P. Hibar, I. B. Hickie, L. E. Hong, J. Horacek, F. M. Howells, H. E. Hulshoff Pol, C. L. Hyde, D. Isaev, A. Jablensky, P. R. Jansen, J. Janssen, E. G. Jonsson, L. A. Jung, R. S. Kahn, Z. Kikinis, K. Liu, P. Klauser, C. Knochel, M. Kubicki, J. Lagopoulos, C. Langen, S. Lawrie, R. K. Lenroot, K. O. Lim, C. Lopez-Jaramillo, A. Lyall, V. Magnotta, R. C. W. Mandl, D. H. Mathalon, R. W. McCarley, S. McCarthy-Jones, C. McDonald, S. McEwen, A. McIntosh, T. Melicher, R. I. Mesholam-Gately, P. T. Michie, B. Mowry, B. A. Mueller, D. T. Newell, P. O'Donnell, V. Oertel-Knochel, L. Oestreich, S. A. Paciga, C. Pantelis, O. Pasternak, G. Pearlson, G. R. Pellicano, A. Pereira, J. Pineda Zapata, F. Piras, S. G. Potkin, A. Preda, P. E. Rasser, D. R. Roalf, R. Roiz, A. Roos, D. Rotenberg, T. D. Satterthwaite, P. Savadjiev, U. Schall, R. J. Scott, M. L. Seal, L. J. Seidman, C. Shannon Weickert, C. D. Whelan, M. E. Shenton, J. S. Kwon, G. Spalletta, F. Spaniel, E. Sprooten, M. Stablein, D. J. Stein, S. Sundram, Y. Tan, S. Tan, S. Tang, H. S. Temmingh, L. T. Westlye, S. Tonnesen, D. Tordesillas-Gutierrez, N. T. Doan, J. Vaidya, N. E. M. van Haren, C. D. Vargas, D. Vecchio, D. Velakoulis, A. Voineskos, J. Q. Voyvodic, Z. Wang, P. Wan, D. Wei, T. W. Weickert, H. Whalley, T. White, T. J. Whitford, J. D. Wojcik, H. Xiang, Z. Xie, H. Yamamori, F. Yang, N. Yao, G. Zhang, J. Zhao, T. G. M. van Erp, J. Turner, P. M. Thompson, G. Donohoe, Widespread 
white matter microstructural differences in schizophrenia across 4322 individuals: results from the ENIGMA Schizophrenia DTI Working Group. Mol Psychiatry, (2017).

72. B. G. Travers, E. D. Bigler, P. M. Tromp do, N. Adluru, A. L. Froehlich, C. Ennis, N. Lange, J. A. Nielsen, M. B. Prigge, A. L. Alexander, J. E. Lainhart, Longitudinal processing speed impairments in males with autism and the effects of white matter microstructure. Neuropsychologia 53, 137-145 (2014).

73. P. Desaunay, A. R. Briant, D. M. Bowler, M. Ring, P. Gerardin, J. M. Baleyte, F. Guenole, F. Eustache, J. J. Parienti, B. Guillery-Girard, Memory in autism spectrum disorder: A meta-analysis of experimental studies. Psychol Bull 146, 377-410 (2020).

74. B. Zikopoulos, H. Barbas, Changes in prefrontal axons may disrupt the network in autism. J Neurosci 30, 14595-14609 (2010).

75. R. C. Gur, D. L. Braff, M. E. Calkins, D. J. Dobie, R. Freedman, M. F. Green, T. A. Greenwood, L. C. Lazzeroni, G. A. Light, K. H. Nuechterlein, A. Olincy, A. D. Radant, L. J. Seidman, L. J. Siever, J. M. Silverman, J. Sprock, W. S. Stone, C. A. Sugar, N. R. Swerdlow, D. W. Tsuang, M. T. Tsuang, B. I. Turetsky, R. E. Gur, Neurocognitive performance in family-based and case-control studies of schizophrenia. Schizophr Res 163, 17-23 (2015).

76. R. S. Keefe, The longitudinal course of cognitive impairment in schizophrenia: an examination of data from premorbid through posttreatment phases of illness. J Clin Psychiatry 75 Suppl 2, 8-13 (2014).

77. B. N. Phan, J. F. Bohlen, B. A. Davis, Z. Ye, H. Y. Chen, B. Mayfield, S. R. Sripathy, S. Cerceo Page, M. N. Campbell, H. L. Smith, D. Gallop, H. Kim, C. L. Thaxton, J. M. Simon, E. E. Burke, J. H. Shin, A. J. Kennedy, J. D. Sweatt, B. D. Philpot, A. E. Jaffe, B. J. Maher, A myelin-related transcriptomic profile is shared by Pitt-Hopkins syndrome models and human autism spectrum disorder. Nat Neurosci 23, 375-385 (2020).

78. A. I. Silva, J. E. Haddon, Y. Ahmed Syed, S. Trent, T. E. Lin, Y. Patel, J. Carter, N. Haan, R. C. Honey, T. Humby, Y. Assaf, M. J. Owen, D. E. J. Linden, J. Hall, L. S. Wilkinson, Cyfip1 haploinsufficient rats show white matter changes, myelin thinning, abnormal oligodendrocytes and behavioural inflexibility. Nat Commun 10, 3455 (2019).

79. C. Marie, A. Clavairoly, M. Frah, H. Hmidan, J. Yan, C. Zhao, J. Van Steenwinckel, R. Daveau, B. Zalc, B. Hassan, J. L. Thomas, P. Gressens, P. Ravassard, I. Moszer, D. M. Martin, Q. R. Lu, C. Parras, Oligodendrocyte precursor survival and differentiation requires chromatin remodeling by Chd7 and Chd8. Proc Natl Acad Sci U S A 115, E8246E8255 (2018).

80. A. Kawamura, Y. Katayama, M. Nishiyama, H. Shoji, K. Tokuoka, Y. Ueta, M. Miyata, T. Isa, T. Miyakawa, A. Hayashi-Takagi, K. I. Nakayama, Oligodendrocyte dysfunction due to Chd8 mutation gives rise to behavioral deficits in mice. Hum Mol Genet 29, 1274 1291 (2020).

81. E. Berret, T. Barron, J. Xu, E. Debner, E. J. Kim, J. H. Kim, Oligodendroglial excitability mediated by glutamatergic inputs and Nav1.2 activation. Nat Commun 8, 557 (2017).

82. M. Schneider, M. Debbane, A. S. Bassett, E. W. Chow, W. L. Fung, M. B. van den Bree, M. Owen, K. C. Murphy, M. Niarchou, W. R. Kates, K. M. Antshel, W. Fremont, D. M. Donald-McGinn, R. E. Gur, E. H. Zackai, J. Vorstman, S. N. Duijff, P. W. Klaassen, A. Swillen, D. Gothelf, T. Green, A. Weizman, A. T. van, L. Evers, E. Boot, V. Shashi, S. R. Hooper, C. E. Bearden, M. Jalbrzikowski, M. Armando, S. Vicari, D. G. Murphy, O. Ousley, L. E. Campbell, T. J. Simon, S. Eliez, Psychiatric Disorders From Childhood to Adulthood in 22q11.2 Deletion Syndrome: Results From the International Consortium on Brain and Behavior in 22q11.2 Deletion Syndrome. Am. J. Psychiatry 171, 627-639 (2014). 
1171 83. N. Hiroi, Critical Reappraisal of Mechanistic Links of Copy Number Variants to Dimensional Constructs of Neuropsychiatric Disorders in Mouse Models. Psychiatry and Clinical Neurosciences 72, 301-321 (2018).

84. J. Dazai, S. Spring, L. S. Cahill, R. M. Henkelman, Multiple-mouse neuroanatomical magnetic resonance imaging. J Vis Exp, e2497 (2011).

85. L. C. Schmued, A rapid, sensitive histochemical stain for myelin in frozen brain sections. J Histochem Cytochem 38, 717-720 (1990).

86. J. H. Venable, R. Coggeshall, A Simplified Lead Citrate Stain for Use in Electron Microscopy. J Cell Biol 25, 407-408 (1965).

87. E. S. Reynolds, The use of lead citrate at high $\mathrm{pH}$ as an electron-opaque stain in electron microscopy. J Cell Biol 17, 208-212 (1963). 


\section{Acknowledgments}

General: We thank Dr. Bernice Morrow for providing the original breeders of $T b \times 1^{+/-}$

1187 mice.

1188 Funding: This study was partly supported by the National Institutes of Health

1189 (R01MH099660, R01DC015776, R21HD053114). The content is solely the responsibility

1190 of the authors and does not necessarily represent the official views of the National

1191 Institutes of Health.

1192 Author Contributions: T. Hiramoto and N. Hiroi designed the study and analyzed all the

1193 data. A. Sumiyoshi, R. Ryoke, H. Nonaka, and R. Kawashima designed and performed

1194 the DTI-MRI study and analyzed the data. T. Yamauchi performed gold staining

1195 immunohistochemistry and qRT-PCR and analyzed the data. G. Kang maintained and

1196 genotyped the mouse colony of $\mathrm{Tb}_{\mathrm{b}} \mathrm{1}^{+-}$mice and performed behavioral studies, except

1197 for the Morris water maze and attentional set shifting tasks. T. Hiramoto performed the

1198 Morris water maze test and analyzed the data. T. Hiramoto., S. Enomoto, and T. Izumi

1199 performed attentional set shifting and analyzed the data. K. Tanigaki performed in vitro

1200 cell cultures of oligodendrocytes and analyzed the data. T. Hiramoto, A. Sumiyoshi, R.

1201 Kato, T. Yamauchi, G. Kang, K. Tanigaki, and N. Hiroi wrote the manuscript.

Competing interests: None

Data and material availability: All data are available upon request. Mice are available through the Material Transfer Agreement. 


\section{Figures}

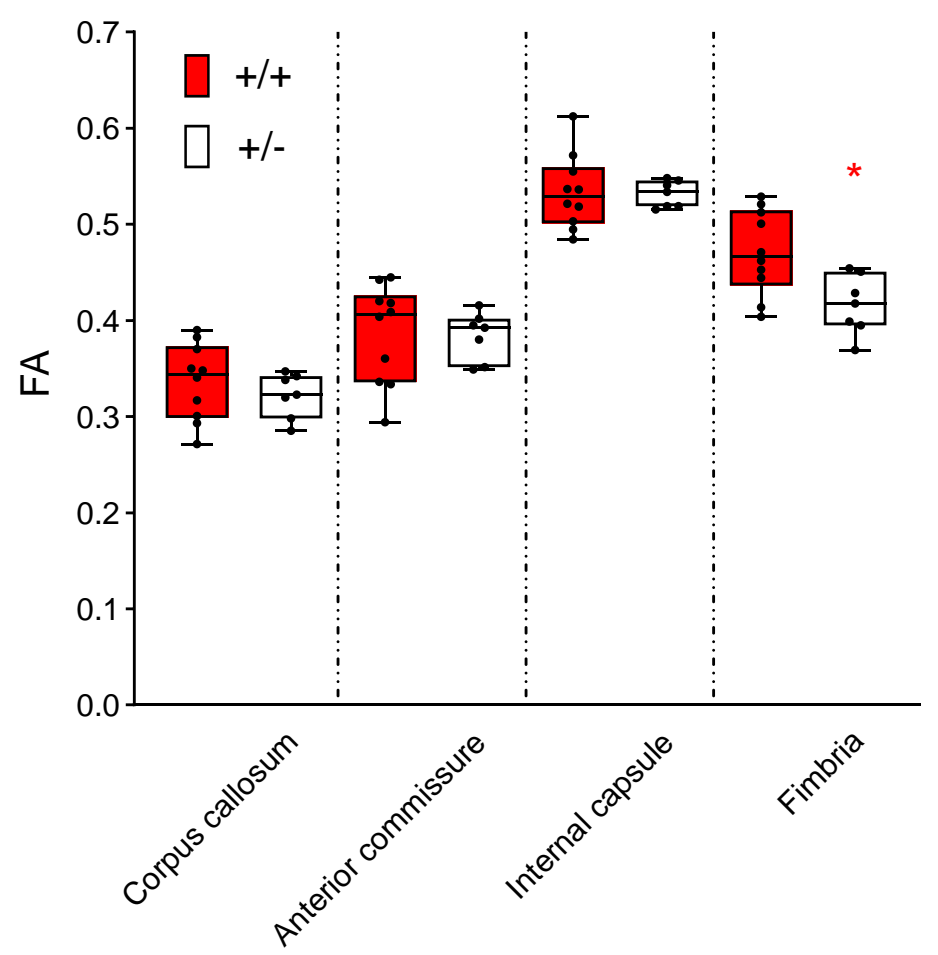

Figure 1. Box-and-Whisker plots of fractional anisotropy (FA) values of the four regions with $F A>0.3$. Analysis using a generalized linear mixed model revealed a regiondependent differential effect of genotype on FA values (Genotype $x$ Region, $F(3,45)=$ 7.337, $\mathrm{P}<0.001)$. Mann-Whitney $U$-tests revealed a significant between-genotype difference in the fimbria only $\left({ }^{*}, U=11, p=0.0185\right) .+/+, n=10 ;+/-, n=7$. 
A

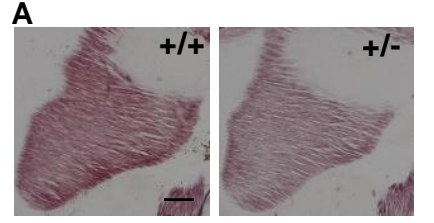

C

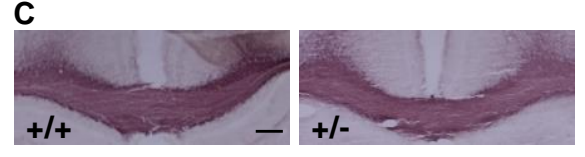

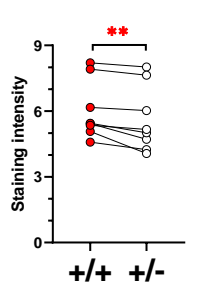

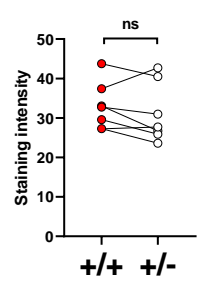

B

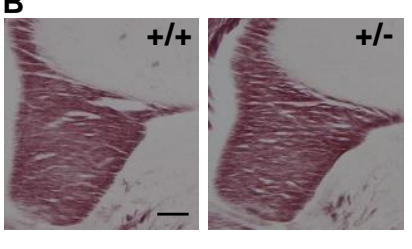

D
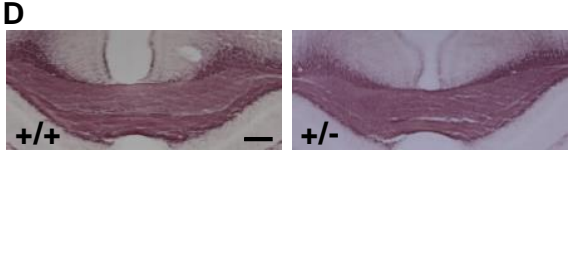
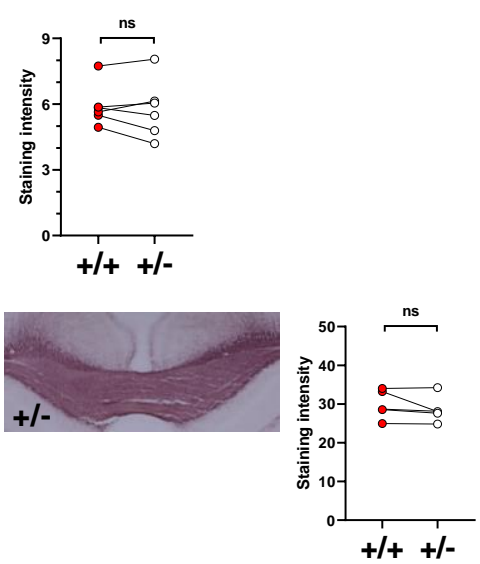

Figure 2. Black-Gold II staining of myelin in the anterior fimbria (A), posterior fimbria (B), anterior corpus callosum (C), and posterior corpus callosum (D) (see Supplemental Fig. S6). Representative images of gold-stained myelin (left panels) and staining intensities of each pair of $+/+$ and +/- mice (right panels) are shown. Given that the assumptions of normality and homogeneity of variance of the raw data from all sections were not met, we used non-parametric Wilcoxon tests for paired $+/+$ and $+/$ - sections of comparable anterior-posterior positions within each slide. Compared with +/+ littermates, +/- mice exhibited significantly decreased levels of gold staining in the anterior fimbria $\left({ }^{* *}, p=\right.$ 0.0078 ), but not in the posterior fimbria (not significant ( $n s), p=0.5625$ ), anterior corpus callosum ( $n s, p=0.2969$ ), or posterior corpus callosum ( $n s, p=0.1875)$. Anterior fimbria, $8+/+$ mice and $8+/-$ mice; posterior fimbria, $6+/+$ mice and $6+/-$ mice; anterior corpus callosum, $7+/+$ mice and $7+/-$ mice; posterior corpus callosum, $5+/+$ mice and $5+/-$ mice. Scale bar $=200 \mu \mathrm{m}$. 


\section{A}
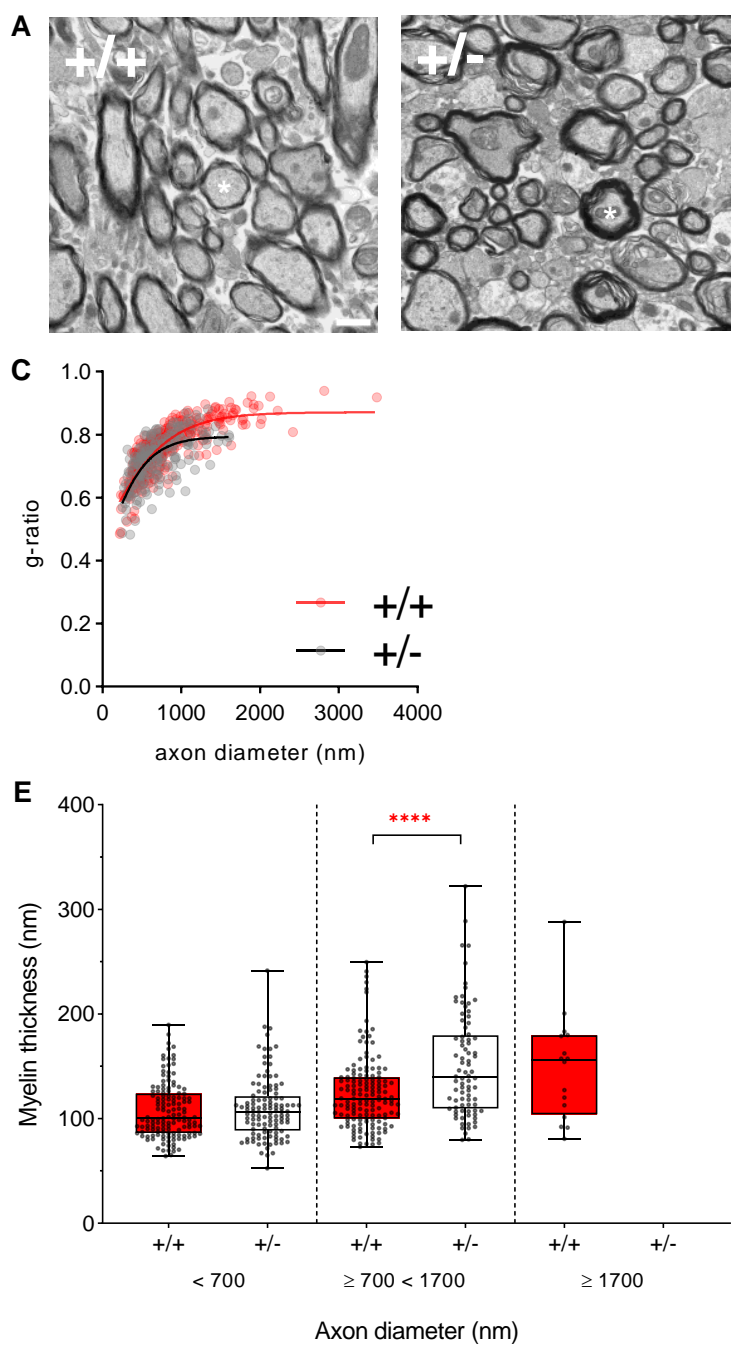

B
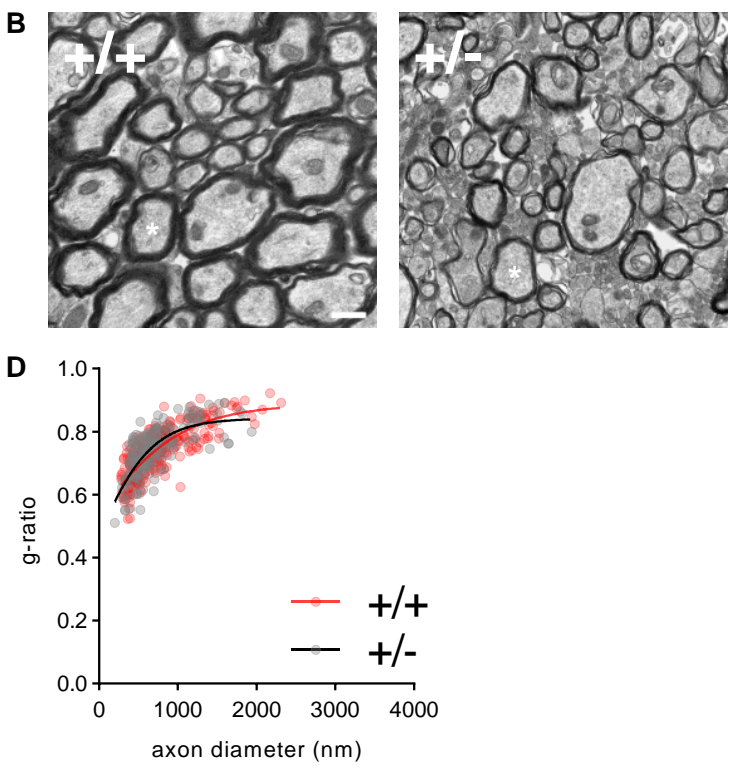

F

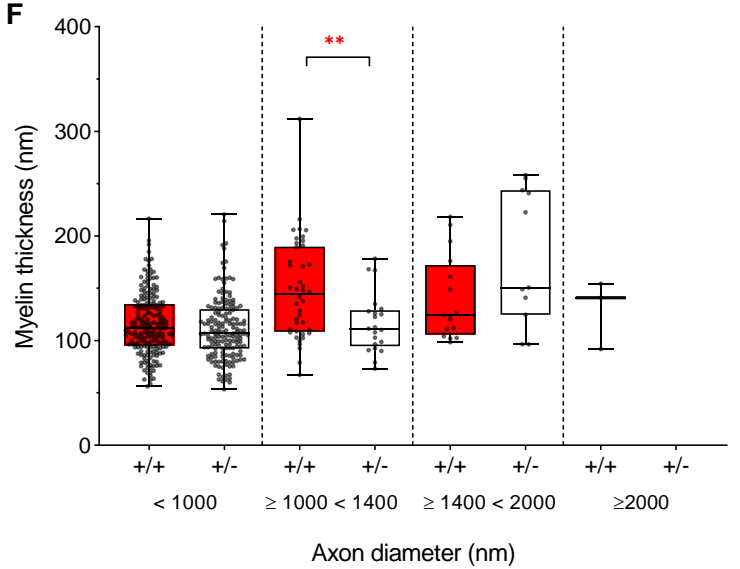

Figure 3 Electron microscopy $(E M)$ images of myelin in the fimbria $(\mathbf{A})$ and corpus callosum (B). We analyzed 300 and 200 axons in the fimbria of both hemispheres in three +/+ and two +/- mice, respectively. We analyzed 260 and 200 axons in the corpus callosum of both hemispheres in $+/+$ and $+/$ - mice, respectively. Ten images were obtained from the fimbria or corpus callosum of each mouse, except for one $+/+$ mouse that had six available images of the corpus callosum. Ten randomly chosen myelinated axons were analyzed from each image. Data from each image and axon were treated as random duplicates. Scale bar $=800 \mathrm{~nm}$. (C) G-ratios in the fimbria across captured images and axons within each image were consistently lower in $+/$ - mice than in $+/+$ mice. Since the normality assumptions were not met $(+/+, p=0.003 ;+/-, p=0.005)$, we used a generalized linear mixed model (Genotype, $F(1,300)=19.539, p<0.001$; Genotype $x$ Image, $F(9,300)=1.011, p=0.431$; Genotype $\times$ Axon, $F(9,300)=0.519, p=$ 0.861 ; Genotype $x$ Image $x$ Axon, $F(81,300)=1.211, p=0.129)$. D) G-ratios in the corpus callosum did not differ between the genotypes (Genotype, $F(1,260)=0.025$, $\mathrm{p}=0.876$; Genotype $\times$ Axon, $\mathrm{F}(9,260)=0.760, \mathrm{p}=0.654$; Genotype $\times$ Image $\times$ Axon, $F(81,260)=1.009, p=0.467)$. The g-ratio was calculated as $g=d / D$, where $d$ and $D$ represent the axon and axon + myelin diameters, respectively. (E,F) Box-and-Whisker plots of myelin thickness $(\mathrm{Y}, \mathrm{nm})$ for a range of axon diameters $(\mathrm{X}, \mathrm{nm})$ in the fimbria $(\mathbf{E})$ and corpus callosum $(\mathbf{F})$. The ranges are based on segments where $+/+$ and $+/$ - differed (see Fig. S7AB). In +/- mice, myelin thickness in the fimbria was increased for axon diameters $\geq 700 \mathrm{~nm}$ and $<1,700 \mathrm{~nm}$ (Mann-Whitney $U=4,202, \mathrm{p}<0.0001,{ }^{* * *}$ ) (see 
1254 white stars in $\mathbf{A}$ ), but not for those with diameters $<700 \mathrm{~nm}$ (Mann-Whitney $\mathrm{U}=7,653, \mathrm{p}$

$1255=0.5473$ ). There were no fimbria axons with diameters $\geq 1700 \mathrm{~nm}$ in $+/$ - mice (see Fig.

1256 S8; Table S1). In +/- mice, myelin thickness in the corpus callosum was decreased for

1257 axons with diameters $\geq 1,000 \mathrm{~nm}$ and $<1,400 \mathrm{~nm}$ (Mann-Whitney $\mathrm{U}=258, \mathrm{p}=0.0071$,

$\left.1258{ }^{* *}\right)$ but not for those with other diameter ranges $(<1,000 \mathrm{~nm}$; Mann-Whitney $\mathrm{U}=14,989, \mathrm{p}$

$1259=0.0881 ; \geq 1,400 \mathrm{~nm}$; Mann-Whitney $\mathrm{U}=56, p=0.1214)$. There were no corpus callosum

1260 axons with diameters $>1,400 \mathrm{~nm}$ axons in $+/$ - mice. 

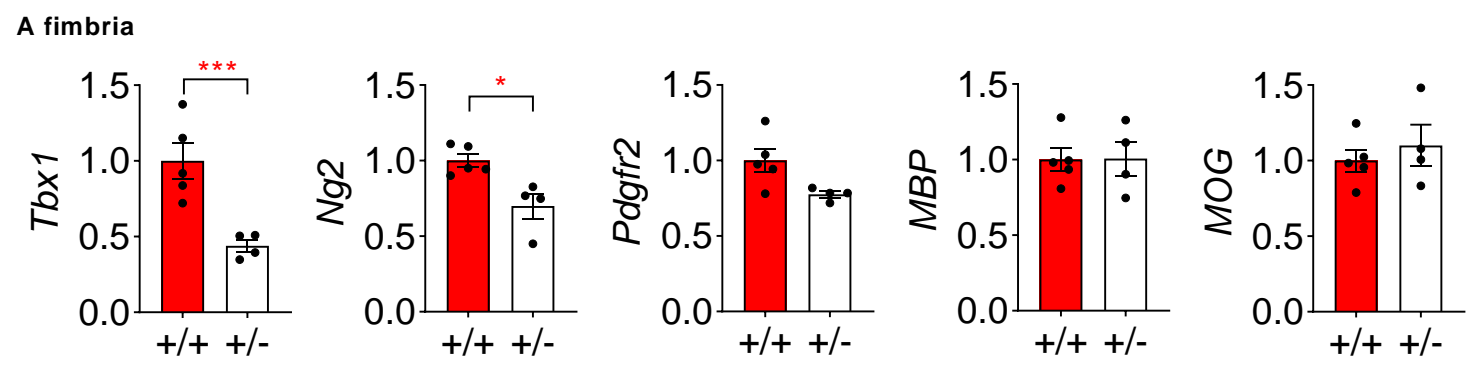

B corpus callosum
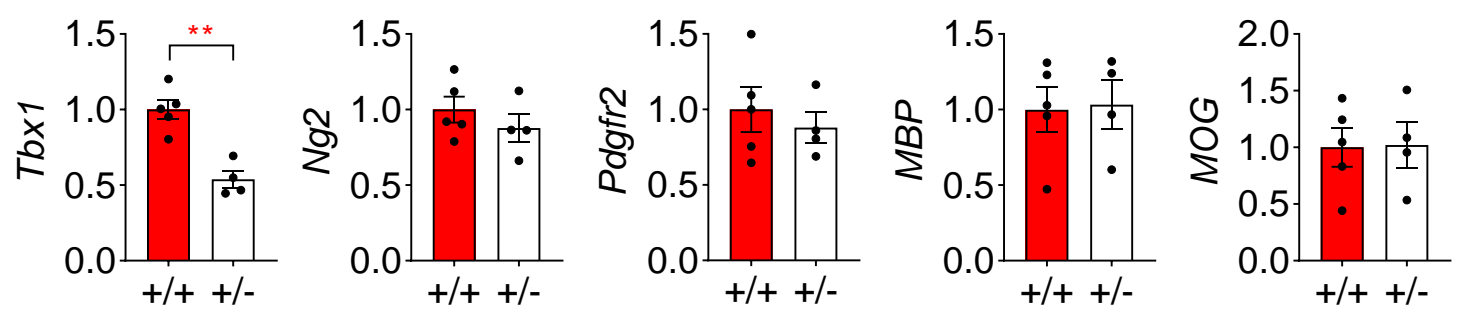

Figure 4. Relative mRNA expression levels (mean \pm standard error of the mean [SEM]) for Tbx1, Ng2, Pdgfr2, myelin basic protein (MBP), and myelin oligodendrocyte glycoprotein (MOG) in the fimbria (A) and corpus callosum (B) of Tbx1+/+ $(n=5)$ and $+/-$ $(n=4)$ mice. Tbx1 mRNA levels were lower in the fimbria $\left(\mathbf{A}, t(7)=4.081, p=0.0047,{ }^{* * *}\right)$ and corpus callosum $\left(B, t(7)=5.221, p=0.0012,{ }^{* *}\right)$ of $+/$ - mice than in those of $+/+$ mice. In the fimbria, levels of $\mathrm{Ng} 2\left(\mathbf{A}, \mathrm{t}(7)=3.394, \mathrm{p}=0.0115,{ }^{*}\right)$ were lower in $+/$ - mice than in $+/+$ mice. These significant differences survived Benjamini-Hochberg's correction at the false discovery rate (FDR) of $5 \%$. There were no other significant differences in the fimbria or corpus callosum (A,B, $\mathrm{p}>0.05)$. 

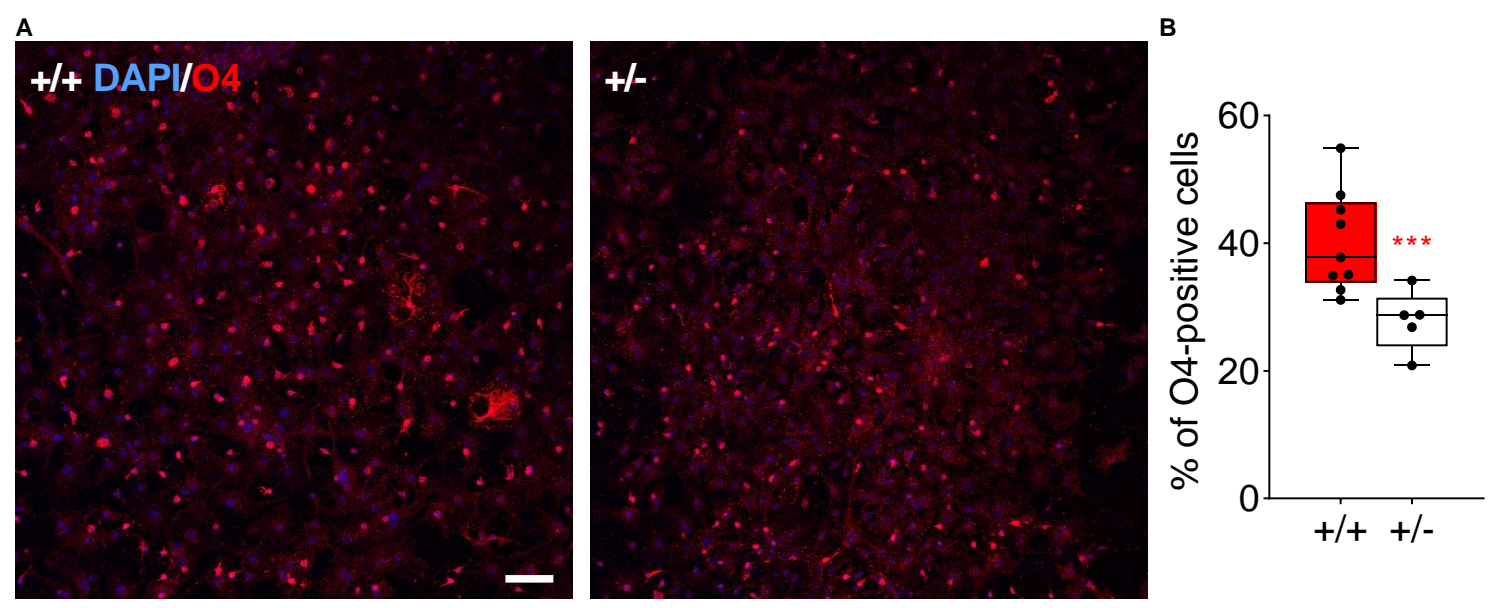

Figure 5. Representative images (A) and Box-and-Whisker plots (B) of O4-positive (red) oligodendrocytes among all DAPI-positive (blue) cells in culture. Since the assumption of normality was not met (Shapiro-Wilk tests: $+/+, W(35)=0.888, p=0.002 ;+/-, W(19)=$ $0.898, p=0.045$ ), we applied a generalized linear mixed model of log transformed data. Progenitor cells derived from the lateral ventricular walls of P21 Tbx1+/- mice produced consistently fewer O4-positive oligodendrocytes than those of $+/+$ mice across the cultures (Genotype, $\mathrm{F}(1,11.451)=12.841 . \mathrm{p}=0.004$, ${ }^{* *}$; Image field, $\mathrm{F}(3,33.978)=$ $0.609, p=0.614$; Genotype $x$ Image field, $F(3,33.978)=0.134, p=0.939)$. Scale bar $=$ $200 \mu \mathrm{m} .+/+, \mathrm{n}=9 ;+/-, \mathrm{n}=5$. 
A

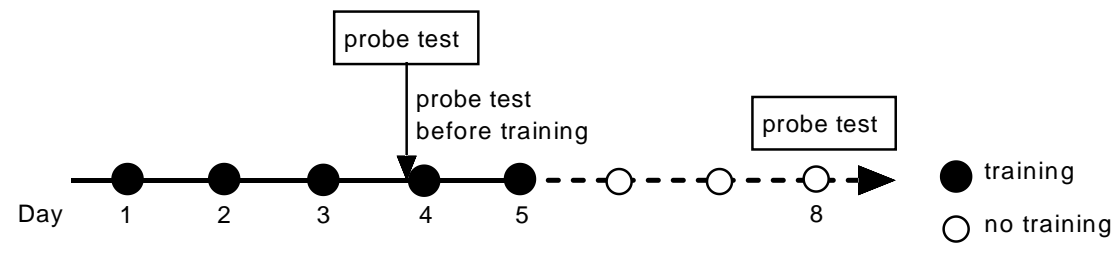

B
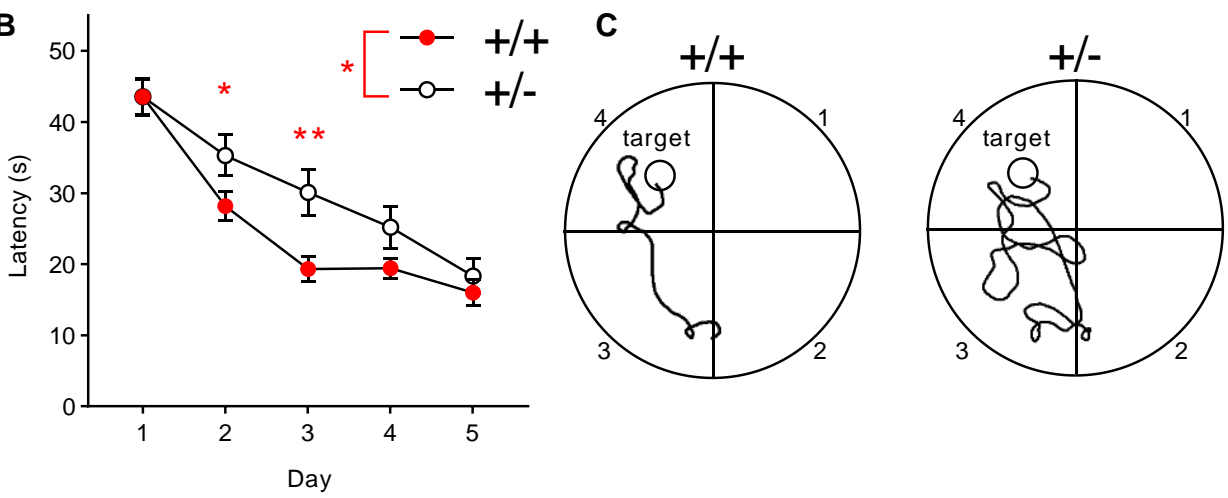

D
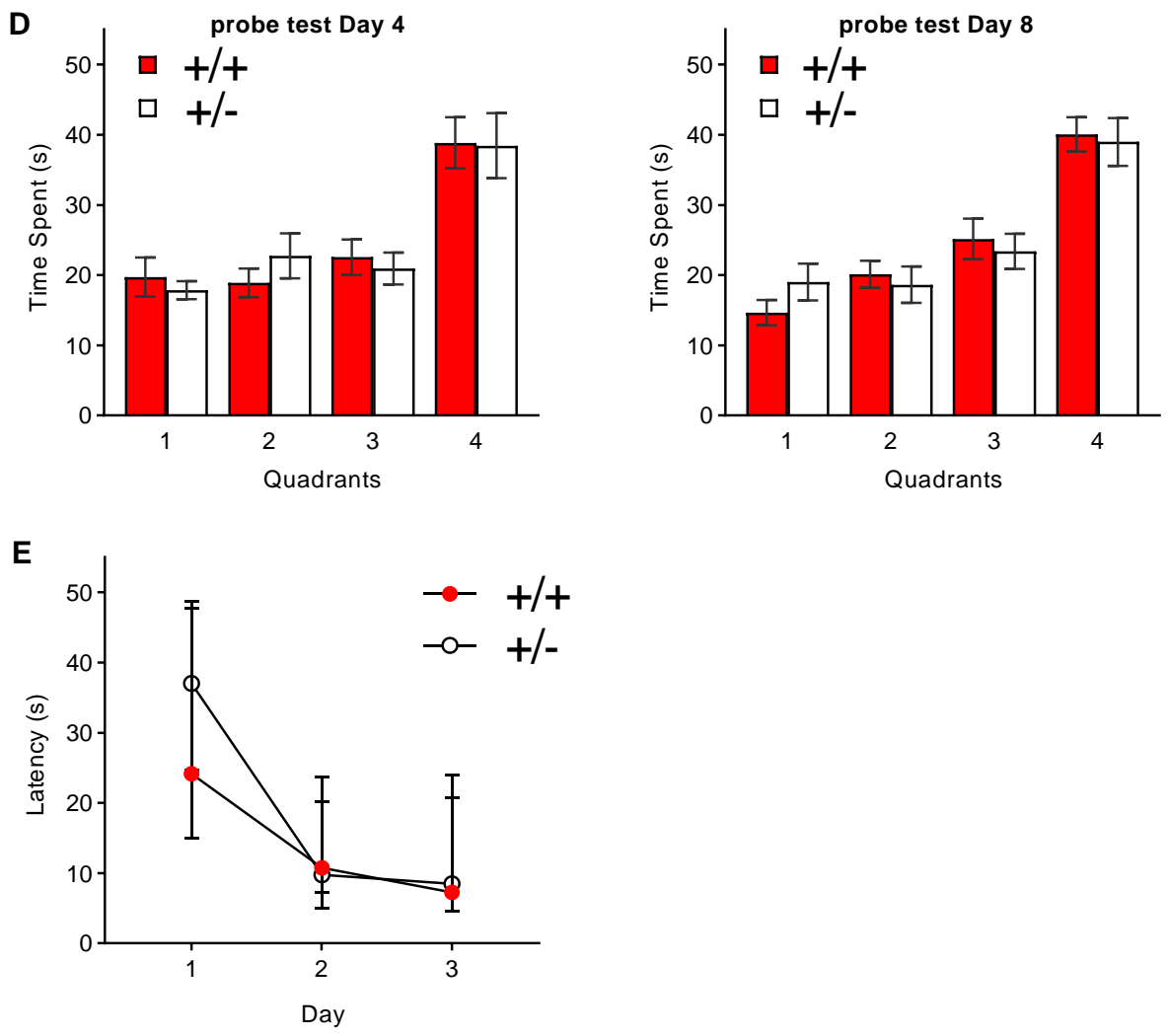

Fig. 6. Performance in the Morris water maze test. (A) Experimental design. (B) The mean ( \pm standard error of the mean [SEM]) escape latency in seconds (s) to the platform during acquisition is plotted against days. Compared with $+/+$ mice, +/- mice exhibited delayed acquisition (Genotype, $F(1,26)=4.643, p=0.041$, $*$; Day, $F(4,104)=55.490$, $p<0.001$; Genotype $\times$ Day, $F(4,104)=2.329, p=0.061)$. The overall genotype effect was primarily due to robust differences on Day $2\left({ }^{*}, p<0.05\right)$ and Day $\left.3{ }^{* *}, p<0.01\right)$, as determined by Newman-Keuls post-hoc tests. $+/+, n=14 ;+/-, n=14$. (C) Representative swim paths of $a+/+$ mouse and $+/$ - mouse on the third training day. The target quadrant included the hidden platform. (D) The mean $( \pm S E M)$ time spent during recall probe tests before training on Day 4 (left) and Day 8 (right). Regardless of the 
1300 quadrant, there were between-genotype differences on Day 4 (Genotype, $F(1,26)=$ 5.597, $\mathrm{p}=0.026$; Quadrant, $\mathrm{F}(3,78)=14.259, \mathrm{p}<0.001$; Genotype $\times$ Quadrant, $F(3,78)=0.295, p=0.829$ ) and Day 8 (Genotype, $F(1,26)=10.207, p=0.004$; Quadrant, $F(3,78)=24.031, p<0.001$; Genotype $\times$ Quadrant, $F(3,78)=0.562, p=$ 0.642 ). The significant main effects of genotype on both days primarily resulted from the generally lower amounts of time spent in three out of the four quadrants in $+/$ - mice (Day 4, Quadrants 1, 3, and 4; Day 8, Quadrants 2, 3, and 4). (E) The mean ( \pm SEM) escape latency in the visible cue task. A separate set of mice underwent examination using this version of the Morris water maze. +/+ and +/- mice equally acquired this task (Genotype, $F(1,17)=1.861, p=0.190 ;$ Day, $F(2,34)=52.313, p<0.001$; Genotype $\times$ Day, $F(2,34)$ $=1.229, \mathrm{p}=0.305)(+/+, \mathrm{n}=8 ;+/-, \mathrm{n}=11)$. 

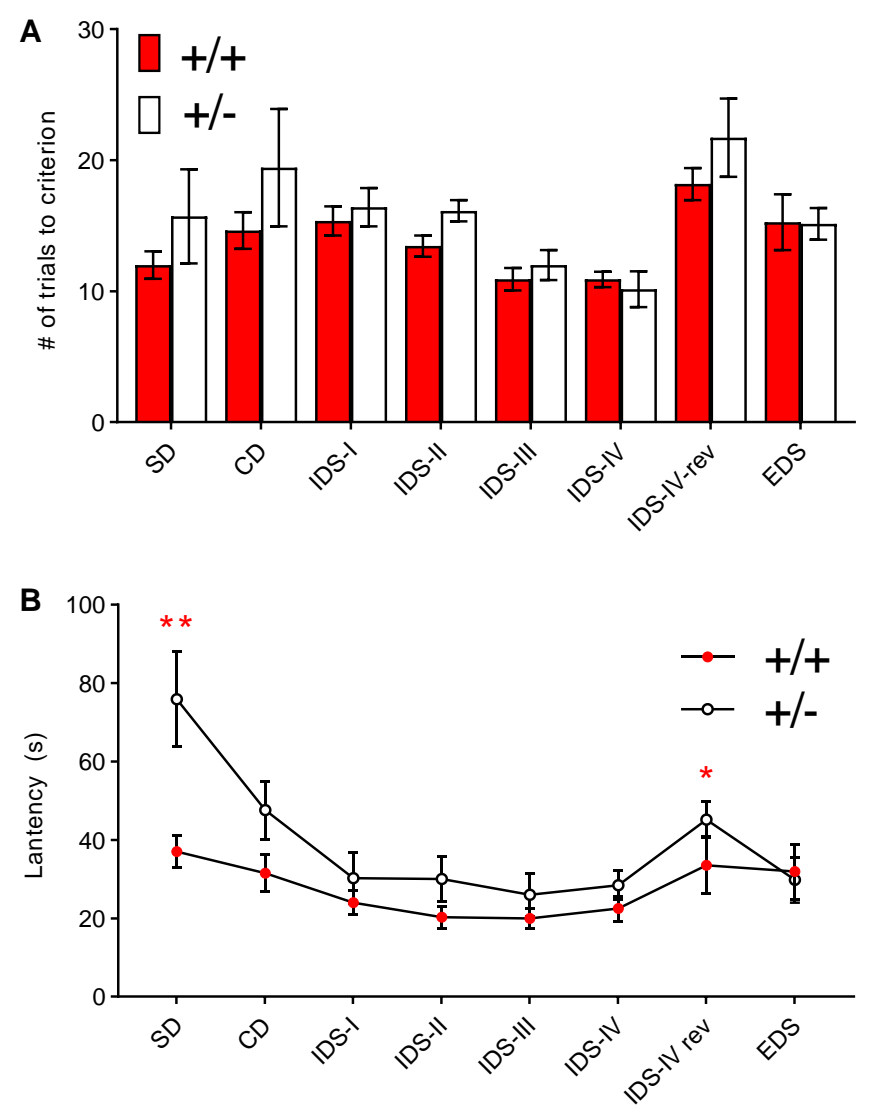

Figure 7. Attentional set shifting. A) The mean number ( \pm standard error of the mean [SEM]) of trials required to reach the criterion (i.e., eight consecutive correct choices). Since the normality assumption was violated $(p=0.002$, at IDS-IV of $+/-)$, we performed analysis using a generalized linear mixed model. There was no between-genotype difference in the number of trials taken to reach the criterion (Genotype, $F(1,16)=1.965$, $p=0.180$; Genotype $\times$ Phase, $F(7,112)=0.824, p=0.569)$. SD, simple discrimination; $\mathrm{CD}$, compound discrimination; IDS, intra-dimensional shift; rev, reversal; EDS, extradimensional shift. (B) The mean latency $( \pm S E M)$ to complete each trial during the first five correct choices. Since the normality assumption was violated $(p=0.001$, at IDSIV rev of $+/+$ ), a generalized linear mixed model was used for analysis. +/- mice were consistently slow in completing this task in a phase-dependent manner (Genotype, $F(1,16)=10.010, p=0.006$; Genotype $x$ Phase, $F(7,112)=2.566, p=0.017)$. MannWhitney non-parametric post hoc comparisons revealed a significant between-genotype difference in latency to completing the two phases of SD $\left({ }^{* *}, p<0.01\right)$ and IDS-IV rev $\left({ }^{*}\right.$, $p<0.05) .+++=11,+/-=7$. 